\title{
Designing a Multistage Supply Chain in Cross-Stage Reverse Logistics Environments: Application of Particle Swarm Optimization Algorithms
}

\author{
Tzu-An Chiang, ${ }^{1}$ Z. H. Che, ${ }^{2}$ and Zhihua Cui ${ }^{3,4}$ \\ ${ }^{1}$ Department of Business Administration, National Taipei College of Business, Taipei 10051, Taiwan \\ ${ }^{2}$ Department of Industrial Engineering and Management, National Taipei University of Technology, Taipei 10608, Taiwan \\ ${ }^{3}$ Complex System and Computational Intelligent Laboratory, Taiyuan University of Science and Technology, Taiyuan 030024, China \\ ${ }^{4}$ State Key Laboratory for Novel Software Technology, Nanjing University, Nanjing 210023, China
}

Correspondence should be addressed to Z. H. Che; zhche@ntut.edu.tw

Received 11 October 2013; Accepted 23 December 2013; Published 18 February 2014

Academic Editors: C. H. Aladag and C.-C. Jane

Copyright (C) 2014 Tzu-An Chiang et al. This is an open access article distributed under the Creative Commons Attribution License, which permits unrestricted use, distribution, and reproduction in any medium, provided the original work is properly cited.

\begin{abstract}
This study designed a cross-stage reverse logistics course for defective products so that damaged products generated in downstream partners can be directly returned to upstream partners throughout the stages of a supply chain for rework and maintenance. To solve this reverse supply chain design problem, an optimal cross-stage reverse logistics mathematical model was developed. In addition, we developed a genetic algorithm (GA) and three particle swarm optimization (PSO) algorithms: the inertia weight method (PSOA_IWM), $V_{\text {Max }}$ method (PSOA_VMM), and constriction factor method (PSOA_CFM), which we employed to find solutions to support this mathematical model. Finally, a real case and five simulative cases with different scopes were used to compare the execution times, convergence times, and objective function values of the four algorithms used to validate the model proposed in this study. Regarding system execution time, the GA consumed more time than the other three PSOs did. Regarding objective function value, the GA, PSOA_IWM, and PSOA_CFM could obtain a lower convergence value than PSOA_VMM could. Finally, PSOA_IWM demonstrated a faster convergence speed than PSOA_VMM, PSOA_CFM, and the GA did.
\end{abstract}

\section{Introduction}

Intense competition within the global market has prompted enterprise competition to change from a competition among companies to that among supply chains. In addition to reducing operating costs and improving competitiveness, effectively integrating the upstream and downstream suppliers and manufacturers of a supply chain can reflect market changes and meet consumer needs efficiently.

Previous studies on the design problems of supply networks include [1-8]. In addition, Che and Cui [9] addressed the network design on unbalanced supply chain system. For the integrity of supply chain circulation, reverse logistics should be implemented to form a complete logistics circulation. Reverse logistics was first proposed by Stock [10]; then Trebilcock [11] indicated that, in the past, most enterprises focused only on forward logistics and misunderstood reverse logistics as a nonprofitable activity.
Cohen [12] suggested that enterprises could save 40\%$60 \%$ of manufacturing costs annually by adopting the remake method, compared with using new materials. In recent years, enterprises have begun paying increased attention to reverse logistics activities such as customer returns, product maintenance, replacement, and recycling. White et al. [13] described in detail the essential aspects and challenges in acquiring, assessing, disassembling, and reprocessing computer equipment as it moves through this reverse manufacturing process. Proper planning of a comprehensive product recycling plan can reduce the environmental damage caused by disposing of used equipment.

Based on literature review, reverse logistics includes management functions related to returned products, depot repair, rework, material reprocessing, material recycling, and disposal of waste and hazardous materials. These allow products to be returned upstream for processing in a reverse logistics system; thus, the circulation of an integral supply chain can be 


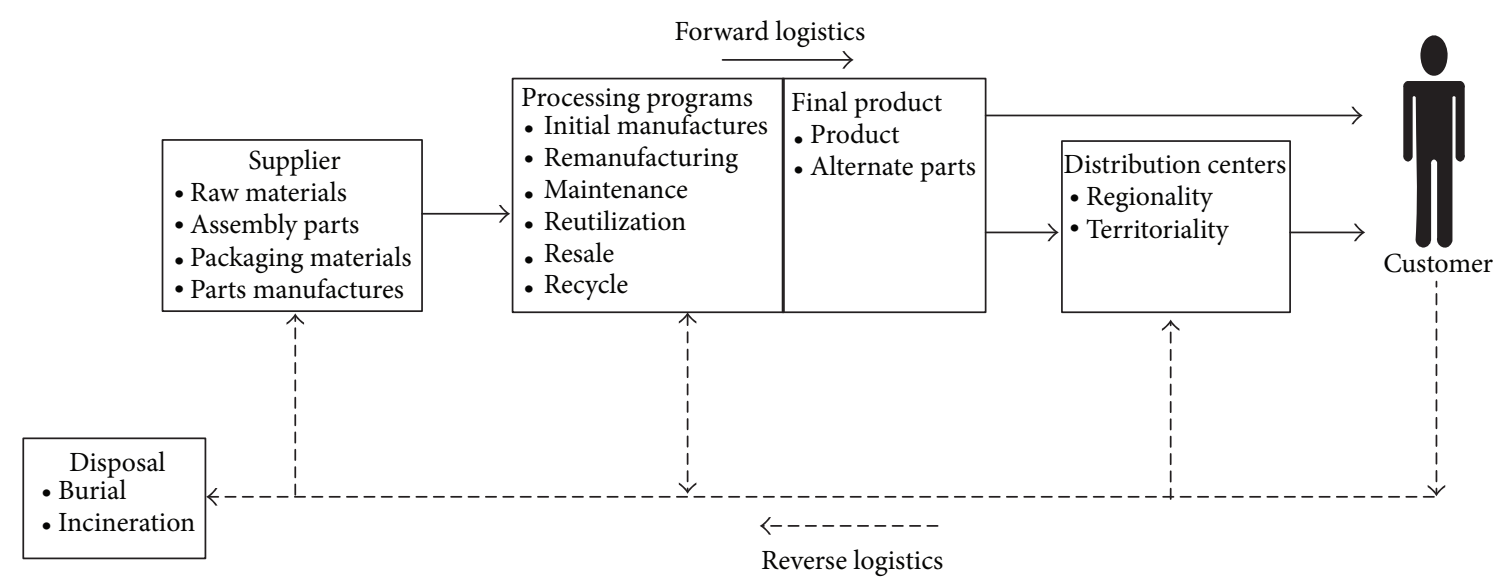

FIGURE 1: The reverse logistics flow of the products (Gattorna [14]).

implemented. The reverse logistics flow of products is shown in Figure 1.

Many scholars have defined reverse logistics briefly and clearly $[10,15-18]$, and some have studied the reverse logistics network design for different fields such as the steel industry [19], electronic equipment [20], sand recycling [21], reusable packaging [22], and general recovery networks [23]. Amini et al. [24] demonstrated how an effective and profitable reverse logistics operation for an RSSC was designed for an MDM in which customer operations demanded a quick repair service. Fleischmann et al. [25] considered a logistics network design in a reverse logistics context and presented a generic facility location model by discussing the differences compared with traditional logistics settings. This model was then used to analyze the impact of product return flow on logistics networks.

In addition, Savaskan et al. [26] developed a detailed understanding of the implications that a manufacturer's reverse channel choice has on forward channel decisions and the used product return rate from customers. Chouinard et al. [27] addressed problems related to integrating reverse logistics activities within an organization and to coordinating this new system. Kainuma and Tawara [28] proposed the multiple-attribute utility theory method for assessing a supply chain, including reusing and recycling throughout the life cycle of products and services. Nagurney and Toyasaki [29] developed a model linking these decisions to prices and material shipments among end-of-life electronics sources, recyclers, processors, and suppliers for deterministic scenarios. Nikolaidis [30] proposed a single-period mathematical model for determining a reverse supply chain plan that considers procurement and returns' remanufacturing, and Nenes and Nikolaidis [31] extended Nikolaidis's model to a multiperiod model. Salema et al. [32] developed a multiperiod, multiproduct model for designing supply chain networks regarding reverse flows. More recently, Pinto-Varela et al. [33] considered an environmental perspective to develop a mixedinteger linear programming model for planning reverse supply chains. Amin and Zhang [34] presented a mixedinteger linear programming model for designing a closedloop supply chain network regarding product life cycles. In addition, Huang et al. [35] analyzed strategies of a closed-loop supply chain containing a dual recycling channel. Although cross-stage logistics in reverse supply chains generally exists in practice, our research suggests that it has yet to be adequately addressed. Hence, the motivation of this study is to design the reverse supply chain with cross-stage logistics.

Reverse logistics is more complex than forward logistics, and this study aimed to develop a mathematical foundation for modeling a cross-stage reverse logistics plan that enables defective products with differing degrees of damage to be returned to upstream partners in the stages of a supply chain for maintenance, replacement, or restructuring. This crossstage reverse logistics model can help save time, lessen unnecessary deliveries, and, more importantly, meet the conditions of reverse logistics operation more efficiently.

Recently, GAs have been regarded as a novel approach to solving complex, large-scale, and real-world optimization problems [6, 36-42]. Moreover, the PSO proposed by Kennedy and Eberhart [43] was an iteration optimization instrument, generating a group of initial solutions at the beginning and then acquiring the optimal value through iteration. Liao and Rittscher [44] applied this instrument to scheduling problems related to industrial piece work requiring minimal completion time. Zhang et al. [45] applied PSO to solve the minimization problems of the project duration for resource-constrained scheduling. Shi et al. [46] applied a PSO to the traveling salesman problem. Che [47] developed a PSO-based back-propagation artificial neural network for estimating the product and mold costs of plastic injection molding and Che [48] proposed a modified PSO method for solving multiechelon unbalanced supply chain planning problems. Priya and Lakshmi [49] applied PSO for performing the real time control of spherical tank system and Ali et al. [50] used the PSO for solving the constrained numerical and engineering benchmark problems. Other related studies concerning the use of PSO for the optimization problems are [51-54].

In addition, Dong et al. [55] compared the improved PSO, a combinatorial particle swarm optimization (CPSO), with GA, and the results showed that the improved PSO was more effective in solving nonlinear problems. Yin and Wang [56] 


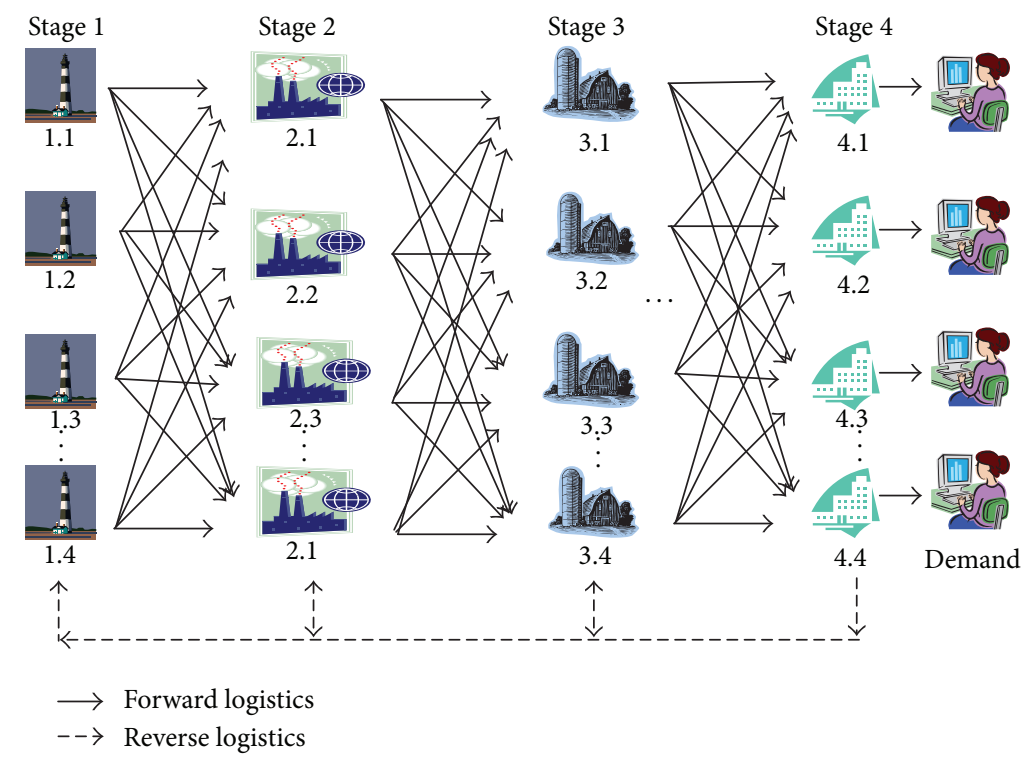

FIGURE 2: The transportation model of reverse logistics.

used PSO to solve nonlinear resource allocation problems and compared PSO with the GA. They found that the efficiency and potency of a PSO were higher than those of a GA. Salman et al. [57] applied PSO to solve the efficiency rates of tasks assigned to computers or parallel computer systems and compared the results with those of GA. The results showed that PSO has faster execution and convergence speeds than the GA. Based on our research, no previous studies have applied PSO to cross-stage reverse logistics problems; therefore, to solve this problem, this study used three updated PSO methods: the inertia weight method (PSOA_IWM), constriction factor method (PSOA_CFM), and $V_{\text {Max }}$ method (PSOA_VMM). The results were then compared with those using the GA regarding system execution time, convergence time, and objective function value.

The remainder of this paper is structured as follows. Section 2 introduces the proposed mathematical foundation and solving algorithms for modeling and solving crossstage reverse logistics problems. Section 3 presents illustrative examples and the comparative and analytical results of the algorithms. Finally, Section 4 provides the conclusion of this study and offers suggestions for future research.

\section{Mathematical Foundation and Solving Models for Cross-Stage Reverse Logistics Problems}

2.1. Problem Description. Reverse logistics activities include recycling, rework, replacement, and waste disposal; however, the reverse logistics activity of each function differs. Therefore, this study designed a forward and reverse cross-stage logistics system for maintaining, reassembling, and packaging recycled defective products. The structure is shown in Figure 2.
When downstream partners generate defective products, the products can be returned directly to upstream supply chain partners for maintenance to restore product function and value, based on the degree of damage. Therefore, this study supposed that, when defective products are generated, they can be divided into $\mathrm{N}$ parts according to the average volume of defective products generated by a particular supplier. Downstream partners can then return defective products, based on the divided quantity, to upstream partners for maintenance. For example, when the first partner of the fourth stage generates defective products, the total defective amount is divided into three parts and then sent to the first, second, and third stage partners separately in the supply chain, thereby reducing general reverse logistics costs and transportation time.

For supply chain partner selection, this study considered productivity restrictions, transportation costs, manufacturing costs, transportation time, manufacturing quality, and other parameters. The $T$-transfer approach is a common statistical technology that is employed to integrate variables. In this study, the $T$-transfer of transportation costs, manufacturing costs, transportation time, and manufacturing quality was integrated into the objective function standards. $T$-transfer is a common statistics technology first proposed by McCall [58]; it is defined as follows: " $T$-Scores are a transformation of raw scores into a standard form, where the transformation is made when there is no knowledge of the population's mean and standard deviation." $T$-scores have a mean of 50 and a standard deviation of 10. Che [59] considered the manufacturing cost and time, transportation cost and time, product quality, and green appraisal score in selecting green suppliers when establishing a green supply chain and used $T$-transfer technology to transform the data. Cost, time, quality, and green appraisal score are measurable criteria with different units; thus, in this study the $T$-transfer approach was 


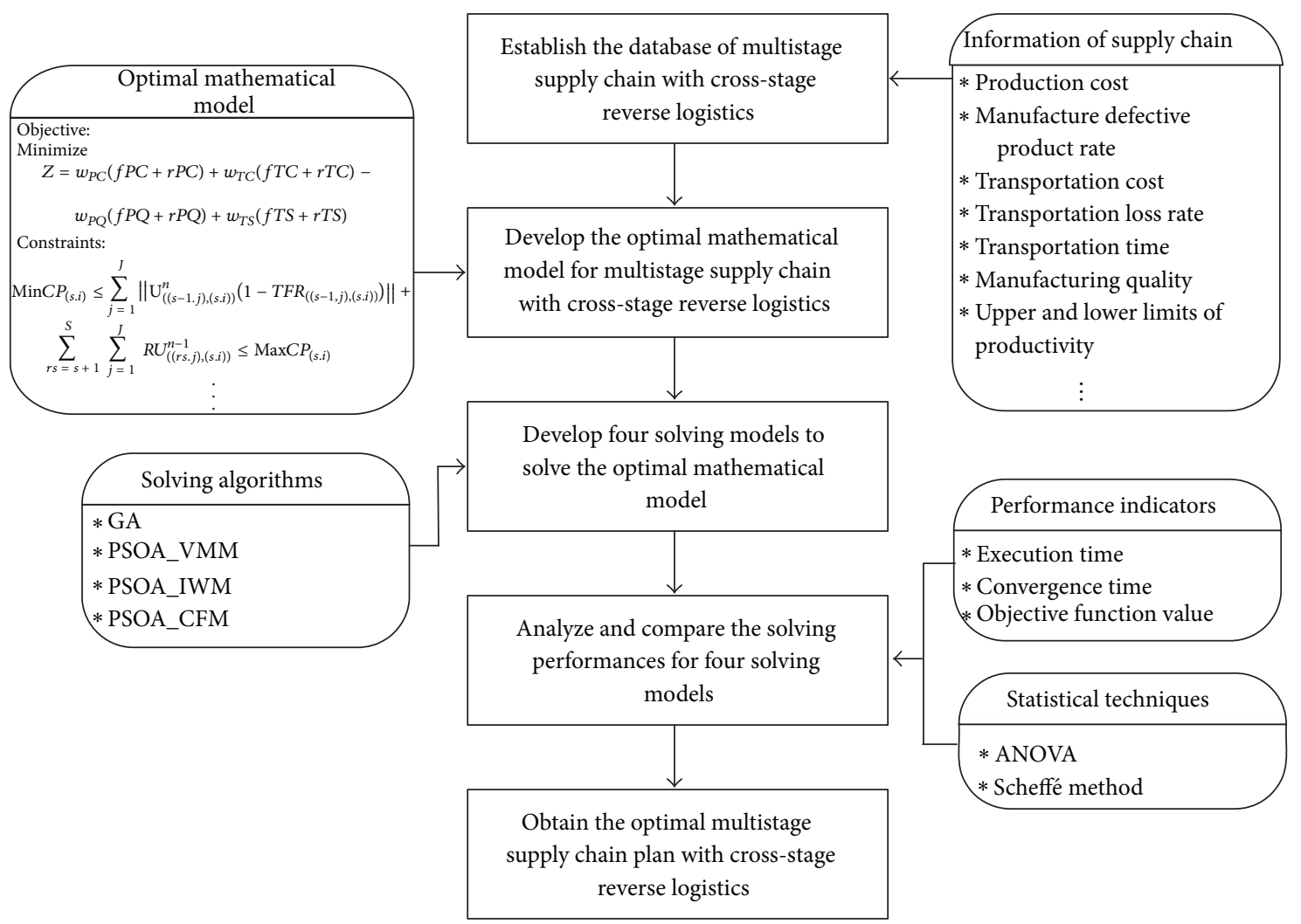

FIGURE 3: The structure of this study.

also employed to first transform the original scores of each criterion into a standard form and then to integrate them.

To satisfy the conditions of the actual production situation, this study used transportation losses and manufacturing losses to construct an unbalanced supply chain network. In considering the characteristics of all the suppliers addressed in this study, we developed a cross-stage reverse logistics course planning system for single-product and multiperiod programming.

We programmed the reverse logistics for recycled defective products, which were returned directly to the upstream supply chain partners for maintenance, reassembly, and repackaging through the cross-stage reverse logistics course programming based on the degree and nature of the damage. For selecting supply chain partners, this study considered the manufacturing characteristics (transportation costs, production costs, upper and lower limit of productivity, manufacturer's defective product rate, transportation losses rate, and manufacturing quality) to construct the reverse logistics programming model. Based on these data, optimal manufacturing quality with minimal production cost, transportation cost, and transportation time can be determined.

In considering the different evaluation criteria, this study $T$-transferred the database and used the Visual Basic program language to compile four solution models, including GA, PSOA_IWM, PSOA_VMM, and PSOA_CFM. The considered parameters in the supplier database were combined to develop a set for designing reverse logistics course planning systems. The framework of this study is shown in Figure 3.
Analysis of variance (ANOVA) and Scheffé analyses were performed to compare the objective function values ( $T$-score), convergence times, and run times of the four algorithms to verify the validity of this study and the performance of the four algorithms.

2.2. Mathematical Foundation for Cross-Stage Reverse Logistics Problems. The optimal mathematical model of crossstage reverse logistics was developed as described in the following steps. The definitions of notations used in this model are listed as follows.

Notations for developing the optimal mathematical model:

\section{Parameters}
$i, j:$
Serial number of supplier
$n:$
$i=1,2,3, \ldots, I ; j=1,2,3, \ldots, J$
$s, r s:$
Production period $n=1,2,3, \ldots, N$
$I, J$ :
$N$ :
$S:$
$C D_{(s . i)}^{n}$ :
Stages of the supply chain network,
$s=1,2,3, \ldots, S ; r s=1,2,3, \ldots, S$
Total number of suppliers
Total production periods
Total stages of supply chain network
Customer requirement of supplier $i$ at stage $s$ for period $n$
$\operatorname{Min} C P_{(s . i)}$ : Minimal starting up productivity of supplier $i$ at stage $s$
$\operatorname{Max} C P_{(s . i)}$ : $\quad$ Maximal starting up productivity of supplier $i$ at stage $s$ 


\begin{tabular}{|c|c|}
\hline$P C_{(s . i)}$ : & $\begin{array}{l}\text { Manufacturing cost of supplier } i \text { at } \\
\text { stage } s\end{array}$ \\
\hline$P Q_{(s . i)}$ : & Product quality of supplier $i$ at stage $s$ \\
\hline$T C_{((s . i),(s+1 . j))}$ & $\begin{array}{l}\text { Transportation cost from supplier } i \text { at } \\
\text { stage } s \text { to supplier } j \text { at stage } s+1\end{array}$ \\
\hline$T S_{((s . i),(s+1 . j))}:$ & $\begin{array}{l}\text { Transportation time from supplier } i \text { at } \\
\text { stage } s \text { to supplier } j \text { at stage } s+1\end{array}$ \\
\hline$\overline{P C}_{(s . i)}:$ & $\begin{array}{l}\text { Average manufacturing cost of supplier } \\
i \text { at stage } s\end{array}$ \\
\hline$\overline{P Q}_{s . i}$ : & $\begin{array}{l}\text { Average product quality of supplier } i \text { at } \\
\text { stage } s\end{array}$ \\
\hline$\overline{T C}_{((s . i),(s+1 . j))}:$ & $\begin{array}{l}\text { Average transportation cost from } \\
\text { supplier } i \text { at stage } s \text { to supplier } j \text { at stage } \\
s+1\end{array}$ \\
\hline$\overline{T S}_{((s . i),(s+1 . j))}:$ & $\begin{array}{l}\text { Average transportation time from } \\
\text { supplier } i \text { at stage } s \text { to supplier } j \text { at stage } \\
s+1\end{array}$ \\
\hline${ }^{T} P C_{(s . i)}:$ & $\begin{array}{l}\text { Manufacturing cost of supplier } i \text { at } \\
\text { stage } s \text { after } T \text {-transfer }\end{array}$ \\
\hline${ }^{T} P Q_{s . i}:$ & $\begin{array}{l}\text { Product quality of supplier } i \text { at stage } s \\
\text { after } T \text {-transfer }\end{array}$ \\
\hline${ }^{T} T C_{((s . i),(s+1 . j))}:$ & $\begin{array}{l}\text { Transportation cost from supplier } i \text { at } \\
\text { stage } s \text { to supplier } j \text { at stage } s+1 \text { after } \\
T \text {-transfer }\end{array}$ \\
\hline${ }^{T} T S_{((s . i),(s+1 . j))}$ & $\begin{array}{l}\text { Transportation time from supplier } i \text { at } \\
\text { stage } s \text { to supplier } j \text { at stage } s+1 \text { after } \\
T \text {-transfer }\end{array}$ \\
\hline$S G_{P C_{s . i}}:$ & $\begin{array}{l}\text { Manufacturing cost standard deviation } \\
\text { of supplier } i \text { at stage } s\end{array}$ \\
\hline$S G_{T C_{((s . i),(s+1 . j))}}:$ & $\begin{array}{l}\text { Transportation cost standard deviation } \\
\text { of supplier } i \text { at stage } s \text { to supplier } j \text { at } \\
\text { stage } s+1\end{array}$ \\
\hline$S G_{P Q_{s . i}}:$ & $\begin{array}{l}\text { Product quality standard deviation of } \\
\text { supplier } i \text { at stage } s\end{array}$ \\
\hline$S G_{T S_{((s . i),(s+1 . j))}}:$ & $\begin{array}{l}\text { Transportation time standard deviation } \\
\text { of supplier } i \text { at stage } s \text { to supplier } j \text { at } \\
\text { stage } s+1\end{array}$ \\
\hline$F R_{(s . i)}:$ & $\begin{array}{l}\text { Defective product rates of supplier } i \text { at } \\
\text { stage } s\end{array}$ \\
\hline $\operatorname{TFR}_{((s . i),(s+1 . j))}:$ & $\begin{array}{l}\text { Transportation loss rate from supplier } i \\
\text { at stage } s \text { to supplier } j \text { at stage } s+1\end{array}$ \\
\hline$w_{P C}, w_{T C}, w_{T S}, w_{P Q}:$ & $\begin{array}{l}\text { Weights of manufacturing cost, } \\
\text { transportation cost, transportation } \\
\text { time, and product quality }\end{array}$ \\
\hline$\|$ \|: & $\begin{array}{l}\text { Integer function for obtaining the } \\
\text { integer value of the real number by } \\
\text { eliminating its decimal. }\end{array}$ \\
\hline
\end{tabular}

Decision Variables

$U_{((s . i),(s+1 . j))}^{n}: \quad$ Transportation quantity from supplier $i$ at stage $s$ to supplier $j$ at stage $s+1$ for period $n$

$R U_{((r s . j),(s . i))}^{n}: \quad$ Defective products quantity from supplier $j$ at stage $r s$ to supplier $i$ at stage $s$ stage for term $n$.
Notations for developing the update models for the position and velocity of each particle:

$c_{1}, c_{2}:$ Learning factors

$K$ : $\quad$ Constriction factor

rand(): Random numbers between 0 and 1

$s_{i}^{*}: \quad$ Pbest memory value of particle $i$

$s_{i}^{\#}: \quad$ Gbest memory value of particle $i$

$s_{i}^{\text {new }}: \quad$ New position of particle $i$

$v_{i}^{\text {old }}: \quad$ Original velocity of particle $i$

$v_{i}^{\text {new }}:$ New velocity of particle $i$

$v_{\max }:$ The set maximal velocity

$w$ : Inertia weight

Totaling of cognition parameter and social

$\phi: \quad$ parameter, which must exceed 4.

Notations for performing hypotheses on the objective function value, convergence time, and completion time among four proposed approaches:

\begin{tabular}{|c|c|}
\hline$C T_{\mathrm{GA}}:$ & Convergence time of GA \\
\hline$C T_{\mathrm{PSOA}}$ & Convergence time of PSOA_IWM \\
\hline$C T_{\text {PSOA_VMM: }}$ & Convergence time of PSOA_VMM \\
\hline$C T_{\text {PSOA_CFM: }}:$ & Convergence time of PSOA_CFM \\
\hline$F T_{\mathrm{GA}}:$ & Completion time of GA \\
\hline$F T_{\mathrm{PSC}}$ & Completion time of PSOA_IWM \\
\hline$F T_{\text {PSOA_VMM }}:$ & Completion time of PSOA_VMM \\
\hline$F T_{\mathrm{PSO}}$ & Completion time of PSOA_CFM \\
\hline $\mathrm{Obj}_{\mathrm{GA}}:$ & Objective function value of GA \\
\hline Obj $_{\text {PSOA_IWM }}:$ & Objective function value of PSOA_IWN \\
\hline Obj $_{\text {PSOA_VMM }}:$ & function value of PSOA_VM \\
\hline $\mathrm{Obj}_{\mathrm{PSOA} \mathrm{Cl}}$ & e of PSOA_CFN \\
\hline
\end{tabular}

Acquire the minimization of manufacturing costs, transportation costs, and transportation time, as well as the maximization of the manufacturing quality of the different suppliers, at various stages of forward and reverse logistics.

Manufacturing cost for forward logistics:

$$
\begin{aligned}
& f P C \\
& \qquad \sum_{n=1}^{N} \sum_{s=1}^{S} \sum_{i=1}^{I}{ }^{T} P C_{(s . i)} \\
& \times\left[\frac{\left\|U_{((s . i),(s+1.1))}^{n}\right\| R_{(s . i)} \|}{\left.1-\sum_{j=2}^{J}\left\|U_{((s-1 . j),(s . i))}^{n}\left(1-T F R_{((s-1, j),(s . i))}\right)\right\|\right] .}\right.
\end{aligned}
$$

Transportation cost for forward logistics:

$$
f T C=\sum_{n=1}^{N} \sum_{s=1}^{S} \sum_{i=1}^{I} \sum_{j=1}^{J}{ }^{T} T C_{(s . i),(s+1, j)} U_{((s . i),(s+1 . j))}^{n} .
$$


Product quality for forward logistics:

$f P Q$

$$
\begin{array}{rl}
=\sum_{n=1}^{N} \sum_{s=1}^{S} \sum_{i=1}^{I}{ }^{T} & P Q_{(s . i)} \\
\times & {\left[\left\|\frac{U_{((s . i),(s+1.1))}^{n}}{1-F R_{(s . i)}}\right\|\right.} \\
& \left.+\sum_{j=2}^{J}\left\|U_{((s-1 . j),(s . i))}^{n}\left(1-\operatorname{TFR}_{((s-1, j),(s . i))}\right)\right\|\right] .
\end{array}
$$

Transportation time for forward logistics:

$$
f T S=\sum_{n=1}^{N} \sum_{s=1}^{S} \sum_{i=1}^{I} \sum_{j=1}^{J}{ }^{T} T S_{(s . i),(s+1, j)} U_{((s . i),(s+1 . j))}^{n} .
$$

Manufacturing cost for reverse logistics:

$$
r P C=\sum_{n=2}^{N} \sum_{s=1}^{S-1} \sum_{i=1}^{I}{ }^{T} P C_{(s . i)} \sum_{r s=s+1}^{S} \sum_{j=1}^{J} R U_{((r s . j),(s . i))}^{n} .
$$

Transportation cost for reverse logistics:

$$
r T C=\sum_{n=2}^{N} \sum_{s=1}^{S} \sum_{i=1}^{I}{ }^{T} T C_{((r s . j),(s . i))} \sum_{r s=s+1}^{S} \sum_{j=1}^{J} R U_{((r s . j),(s . i))}^{n} .
$$

Product quality for reverse logistics:

$$
r P Q=\sum_{n=2}^{N} \sum_{s=1}^{S-1} \sum_{i=1}^{I}{ }^{T} P Q_{(s . i)} \sum_{r s=s+1}^{S} \sum_{j=1}^{J} R U_{((r s . j),(s . i))}^{n} .
$$

Transportation time for reverse logistics:

$$
r T S=\sum_{n=2}^{N} \sum_{s=1}^{S} \sum_{i=1}^{I} T S_{((r s . j),(s . i))} \sum_{r s=s+1}^{S} \sum_{j=1}^{J} R U_{((r s . j),(s . i))}^{n}
$$

The objective function is expressed as follows:

$$
\text { Minimize } \quad \begin{aligned}
Z & =w_{P C}(f P C+r P C) \\
& +w_{T C}(f T C+r T C) \\
& -w_{P Q}(f P Q+r P Q) \\
& +w_{T S}(f T S+r T S)
\end{aligned}
$$

s.t.
Upper and lower limits of productivity of all the suppliers:

$$
\begin{aligned}
& \operatorname{Min} C P_{(s . i)} \leq \sum_{j=1}^{J}\left\|U_{((s-1 . j),(s . i))}^{n}\left(1-\operatorname{TFR}_{((s-1, j),(s . i))}\right)\right\| \\
&+\sum_{r s=s+1}^{S} \sum_{j=1}^{J} R U_{((r s . j),(s . i))}^{n-1} \leq \operatorname{Max} C P_{(s . i)} \\
& \qquad \text { for } n=1,2,3, \ldots, N ; \\
& \operatorname{Min} C P_{(s . i)} \leq \sum_{j=1}^{J} \| \frac{U_{((s . i),(s+1 . j))}^{n} \|}{1-F R_{(s . i)} \|} \quad i=1,2,3, \ldots, I ; \\
&+\sum_{r s=s+1}^{S} \sum_{j=1}^{J} R U_{((r s . j),(s . i))}^{n-1} \leq \operatorname{Max} C P_{(s . i)} \\
& \text { for } n=1,2,3, \ldots, N ; \quad s=1 ; \\
& i=1,2,3, \ldots, I .
\end{aligned}
$$

Ensure the balance between the input and output of all partners by considering the transportation defective rate:

$$
\begin{aligned}
& \sum_{j=1}^{J}\left\|U_{((s-1 . j),(s . i))}^{n}\left(1-\operatorname{TFR}_{((s-1, j),(s . i))}\right)\right\| \\
& +\sum_{r s=s+1}^{S} \sum_{j=1}^{J} R U_{((r s . j),(s . i))}^{n-1} \\
& =\sum_{j=1}^{J} U_{((s+1 . j),(s . i))}^{n}+\sum_{r s=1}^{s-1} \sum_{j=1}^{J} R U_{((s . i),(r s . j))}^{n} \\
& \quad \text { for } n=1,2,3, \ldots, N ; \\
& \quad s=1,2,3, \ldots, S ; \quad i=1,2,3, \ldots, I
\end{aligned}
$$

$$
\sum_{r s=1}^{s} \sum_{j=1}^{J} R U_{((r s . j),(s . i))}^{n}
$$

$$
\begin{gathered}
=\|\left(\sum_{j=1}^{J}\left\|U_{((s-1 . j),(s . i))}^{n}\left(1-T F R_{((s-1, j),(s . i))}\right)\right\|\right. \\
\left.+\sum_{r s=s+1}^{S} \sum_{j=1}^{J} R U_{((r s . j),(s . i))}^{n-1}\right) F R_{(s . i)} \| \\
\quad \text { for } n=1,2,3, \ldots, N ; \\
\quad s=1,2,3, \ldots, S ; \quad i=1,2,3, \ldots, I .
\end{gathered}
$$


The product quantity should meet customer requirements:

$$
\begin{array}{r}
\sum_{j=1}^{J}\left\|U_{((s-1 . j),(s . i))}^{n}\left(1-\operatorname{TFR}_{((s-1, j),(s . i))}\right)\right\| \\
-\sum_{r s=1}^{s-1} \sum_{j=1}^{J} R U_{((s . i),(s-r s . j))}^{n}=C D_{(s . i)}^{n} \\
\text { for } n=1,2,3, \ldots, N ; \quad s=S \\
i=1,2,3, \ldots, I .
\end{array}
$$

The weights of manufacturing cost, transportation cost, transportation time, and product quality should be not less than 0 and not more than 1 :

$$
\begin{aligned}
& 0 \leq w_{P C}, w_{T C}, w_{T S}, w_{P Q} \leq 1 \\
& w_{P C}+w_{T C}+w_{T S}+w_{P Q}=1 .
\end{aligned}
$$

The defective products returned in the first period during the multiperiods of production number zero:

$$
\begin{array}{r}
R U_{((r s . j),(s, i))}^{n}=0 \quad \text { for } n \leq 0 ; s=1,2,3,4, \ldots, S-1 ; \\
r s=s+1, \ldots, S ; \quad \begin{array}{r}
i=1,2,3, \ldots, I ; \\
j=1,2,3, \ldots, J .
\end{array}
\end{array}
$$

The forward and reverse transportation volume must be larger than zero and be an integer:

$$
\begin{aligned}
& U_{((s . i),(s+1 . j))}^{n} \geq 0 \text { and } U_{((s . i),(s+1 . j))}^{n} \in \text { Integer } \\
& \text { for } n=1,2,3, \ldots, N ; \quad s=1,2,3, \ldots, S ; \\
& \quad i=1,2,3, \ldots, I ; \quad j=1,2,3, \ldots, J \\
& R U_{((r s . j),(s . i))}^{n} \geq 0 \text { and } U_{((s . i),(s+1 . j))}^{n} \in \text { Integer } \\
& \quad \text { for } s=1,2,3, \ldots, S ; \quad r s=S+1, \ldots S \\
& n=1,2,3, \ldots, N ; \quad i=1,2,3, \ldots, I ; \quad j=1,2,3, \ldots, J
\end{aligned}
$$

Manufacturing costs, transportation costs, manufacturing quality, and transportation time should be $T$-transferred:

$$
\begin{array}{r}
{ }^{T} P C_{(s . i)}=\frac{P C_{(s . i)}-\overline{P C_{(s . i)}}}{S G_{P C_{(s . i)}} / 10}+50 \quad \text { for } s=1,2,3, \ldots, S ; \\
i=1,2,3, \ldots, I ; \\
{ }^{T} T C_{((s . i),(s+1 . j))}=\frac{T C_{((s . i),(s+1 . j))}-\overline{T C}_{((s . i),(s+1 . j))}}{S G_{T C_{((s . i),(s+1 . j))}} / 10}+50 \\
\text { for } s=1,2,3, \ldots, S ; \quad i=1,2,3, \ldots, I ; \\
j=1,2,3, \ldots, J
\end{array}
$$

$$
\begin{gathered}
{ }^{T} P Q_{(s . i)}=\frac{P Q_{(s . i)}-\overline{P Q}_{(s . i)}}{S G_{P Q_{(s . i)}} / 10}+50 \quad \text { for } s=1,2,3, \ldots, S ; \\
i=1,2,3, \ldots, I ; \\
{ }^{T} T S_{((s . i),(s+1 . j))}=\frac{T S_{((s . i),(s+1 . j))}-\overline{T S}_{((s . i),(s+1 . j))}}{S G_{T S_{((s . i),(s+1 . j))}} / 10}+50 \\
\text { for } s=1,2,3, \ldots, S ; \quad i=1,2,3, \ldots, I ; \\
j=1,2,3, \ldots, J .
\end{gathered}
$$

\subsection{Proposed Models for Solving Cross-Stage Reverse Logistics Problems}

2.3.1. GA-Solving Model. The detailed procedures of a GAsolving model are described as follows.

Step 1. The encoding of this study was performed according to the cross-stage reverse logistics problem including forward and reverse transportation routes; therefore, one route is one encoding value. The scope is randomly generated based on the demands and (10)-(14). The chromosome structure is shown in Figure 4. The gene cell index 1.1-2.1 in the figure represents the products sent from the first supplier of the first stage to the initial supplier of the second stage within the supply chain structure, whereas the gene value represents the transportation volumes from upstream to downstream.

Step 2. Substitute all the generated encoding values in the objective function equation (1) of this study to acquire the fitness function value of each gene.

Step 3. This study adopted the roulette wheel selection proposed by Goldberg [60], which is performed before cloning to solve the minimization problem of this study. It then selects the reciprocal of fitness function generated in Step 2 and calculates the cumulative probability of each strip of chromosome; the larger probability value indicates that this chromosome has a greater likelihood of being duplicated. One probability value between 0 and 1 is generated, the suitable fitness function is determined, and cloning is carried out.

Step 4. The crossover of this study involves using the singlepoint crossover method. Randomly select two chromosomes from the parent body for crossover, and generate one crossover point, then exchange the genes of the chromosome. The crossover course is shown in Figure 5.

Step 5. The mutation of this study also adopts a single-point mutation method and treats the delivery route of one supplier as a "single-point" of value. The mutation method is shown in Figure 6.

Step 6. The new filial generation was generated through the gene evolution of Steps 3-5; if the optimal fitness function value of the filial generation is higher than that of the parental 


\begin{tabular}{|c|c|c|c|c|c|c|c|c|c|c|c|c|}
\hline Gene cell index & $1.1-2.1$ & $1.2-2.1$ & $1.3-2.1$ & $1.1-2.2$ & $1.2-2.2$ & $1.3-2.2$ & $\cdots$ & $3.1-4.6$ & $3.2-4.6$ & $3.3-4.6$ & $3.4-4.6$ & $3.5-4.6$ \\
\hline Gene value & 236 & 224 & 115 & 75 & 55 & 69 & $\ldots$ & 75 & 65 & 78 & 99 & 63 \\
\hline
\end{tabular}

FIGURE 4: Chromosome structure.

\begin{tabular}{|c|c|c|c|c|c|c|c|c|c|c|c|c|}
\hline \multicolumn{13}{|l|}{ Parent-1 } \\
\hline Gene cell index & $\mid 1.1-2.1$ & $1.2-2.1$ & $1.3-2.1$ & $1.1-2.2$ & $1.2-2.2$ & $1.3-2.2$ & 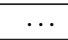 & $3.1-4.6$ & $3.2-4.6$ & $3.3-4.6$ & $3.4-4.6$ & $3.5-4.6$ \\
\hline Gene value & 236 & 224 & 115 & 75 & 55 & 69 & $\ldots$ & 75 & 65 & 78 & 99 & 63 \\
\hline \multicolumn{13}{|l|}{ Parent-2 } \\
\hline Gene cell index & $1.1-2.1$ & $1.2-2.1$ & $1.3-2.1$ & $1.1-2.2$ & $1.2-2.2$ & $1.3-2.2$ & $\cdots$ & $3.1-4.6$ & $3.2-4.6$ & $3.3-4.6$ & $3.4-4.6$ & $3.5-4.6$ \\
\hline Gene value & 89 & 56 & 32 & 63 & 99 & 96 & $\cdots$ & 45 & 56 & 32 & 106 & 88 \\
\hline & & & & After & crossove & & Crosso & er point & & & & \\
\hline \multicolumn{13}{|l|}{ Child-1 } \\
\hline Gene cell index & $1.1-2.1$ & $1.2-2.1$ & $1.3-2.1$ & $1.1-2.2$ & $1.2-2.2$ & $1.3-2.2$ & $\cdots$ & $3.1-4.6$ & $3.2-4.6$ & $3.3-4.6$ & $3.4-4.6$ & $3.5-4.6$ \\
\hline Gene value & 236 & 224 & 115 & 75 & 55 & 69 & $\ldots$ & 45 & 56 & 32 & 106 & 88 \\
\hline \multicolumn{13}{|l|}{ Child-2 } \\
\hline Gene cell index & $1.1-2.1$ & $1.2-2.1$ & $1.3-2.1$ & $1.1-2.2$ & $1.2-2.2$ & $1.3-2.2$ & $\cdots$ & $3.1-4.6$ & $3.2-4.6$ & $3.3-4.6$ & $3.4-4.6$ & $3.5-4.6$ \\
\hline Gene value & 89 & 56 & 32 & 63 & 99 & 96 & $\cdots$ & 75 & 65 & 78 & 99 & 63 \\
\hline
\end{tabular}

FIGURE 5: Crossover process.

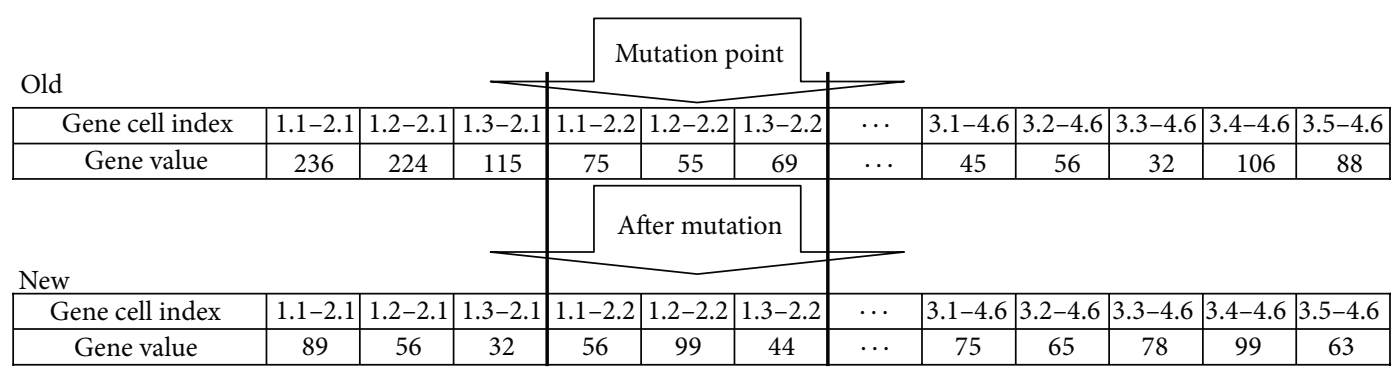

Figure 6: Mutation process.

\begin{tabular}{|c|c|c|c|c|c|c|c|c|c|c|}
\hline Particle & 1 & 2 & 3 & 4 & 5 & 6 & $\cdots$ & 60 & 61 & 62 \\
\hline Line & ${ }^{1.1-2.2} \mathrm{~F}$ & ${ }^{1.1-2.2} \mathrm{~F}$ & ${ }^{1.1-2.3} \mathrm{~F}$ & ${ }^{1.1-2.4} \mathrm{~F}$ & ${ }^{1.2-2.1} \mathrm{~F}$ & ${ }^{1.2-2.2} \mathrm{~F}$ & $\cdots$ & ${ }^{3.3-4.6} \mathrm{~F}$ & ${ }^{3.4-4.6} \mathrm{~F}$ & ${ }^{3.5-4.6} \mathrm{~F}$ \\
\hline Volume & 103 & 27 & 30 & 140 & 158 & 18 & $\cdots$ & 308 & 15 & 61 \\
\hline
\end{tabular}

FIGURE 7: Particle swarm encoding for forward logistics.

\begin{tabular}{|c|c|c|c|c|c|c|c|c|c|c|}
\hline Particle & 1 & 2 & 3 & 4 & 5 & 6 & $\ldots$ & 117 & 118 & 119 \\
\hline Line & ${ }^{2.1-1.1} \mathrm{R}$ & $2.1-1.2 \mathrm{R}$ & $2.1-1.3 \mathrm{R}$ & $2.2-1.1 \mathrm{R}$ & $2.2-1.2 \mathrm{R}$ & $2.2-1.3 \mathrm{R}$ & $\ldots$ & $4.6-3.3 \mathrm{R}$ & ${ }^{4.6-3.4} \mathrm{R}$ & $4.6-3.5 \mathrm{R}$ \\
\hline Volume & 0 & 0 & 42 & 9 & 0 & 0 & $\ldots$ & 0 & 2 & 0 \\
\hline
\end{tabular}

FIGURE 8: Particle swarm encoding for reverse logistics.

generation, then this would replace the parental generation as the new parent generation; otherwise, the original parental generation would be reserved to conduct the evolution of the next generation.

Step 7. This study sets the iteration times as the termination condition for gene evolution.

2.3.2. PSO-Solving Models. The detailed procedures involved in PSO-solving models are described as follows.

Step 8. Set the relative coefficients as particle population, velocity, weight, and iteration times; then all forward and reverse transportation routes are viewed as one particle based on the supply chain structure. The forward and reverse particle swarm encodings are shown in Figures 7 and 8, $1.1-2.1_{\mathrm{F}}$ in Figure 7 represents the products sent from the first supplier of the first stage to the first supplier of the second stage, and $2.1-1.1_{\mathrm{R}}$ in Figure 8 represents the products returned to the first suppliers of the first stage from the first suppliers of the second stage.

The forward transportation volume produces the parental generation solution, adopting demand, transportation loss, manufacturer's defective products, and (10)-(14) as the random variant scope for the particles. Each particle has its own 
initial parameters of velocity and position, generated within the scope of $0-1$. The velocity and position would be renewed, and the reverse part is delivered according to the proportion, based on the quantity of defective products generated by the downstream suppliers of each stage. For example, the defective products generated by the fourth stage retailer would first be divided into $30 \%, 30 \%$, and $40 \%$, according to the proportion, and then delivered to the suppliers of the third, second, and first stages.

Step 9. All particles received by the initial solutions of objective function equation (1) are carried to conduct the operation to achieve minimal transportation costs, transportation times, and manufacturing costs, as well as maximizing the manufacturing quality for each granule particle.

Step 10. The target value of each particle generated in Step 9 is compared to receive Gbest.

Step 11. Modify the Pbest and Gbest. If the Pbest is better than the Gbest, then the Pbest would replace the Gbest.

Step 12. For the renewal portion of this study, the inertia weight method (PSOA_IWM) proposed by Eberhart and Shi [61], the constriction factor method (PSOA_CFM) proposed by Clerc [62], and the $V_{\text {Max }}$ method (PSOA_VMM) proposed by Eberhart and Kennedy [43, 63] were used to update the position and velocity of each particle. The updated modes are listed as follows (descriptions of notations are listed in the appendix).

(1) PSOA_IWM (Eberhart and Shi [61]):

$$
\begin{gathered}
v_{i}^{\text {new }}=w v_{i}^{\text {old }}+c_{1} \times \operatorname{rand}() \times\left(s_{i}^{*}-s_{i}^{\text {old }}\right)+c_{2} \\
\times \operatorname{rand}() \times\left(s_{i}^{\#}-s_{i}^{\text {old }}\right), \\
s_{i}^{\text {new }}=s_{i}^{\text {old }}+v_{i}^{\text {new }} .
\end{gathered}
$$

(2) PSOA_VMM (Eberhart and Kennedy $[43,63])$ :

$$
\begin{gathered}
v_{i}^{\text {new }}=v_{i}^{\text {old }}+c_{1} \times \operatorname{rand}() \times\left(s_{i}^{*}-s_{i}^{\text {old }}\right)+c_{2} \\
\times \text { rand }() \times\left(s_{i}^{\#}-s_{i}^{\text {old }}\right), \\
s_{i}^{\text {new }}=s_{i}^{\text {old }}+v_{i}^{\text {new }} \\
\quad \text { if } v_{i}>v_{\text {max }}, \quad v_{i}=v_{\max } \\
\text { else if } v_{i}<-v_{\text {max }}, \quad v_{i}=-v_{\max } .
\end{gathered}
$$

When the particle velocity was too extreme, it could be guided to the normal velocity vector.

(3) PSOA_CFM (Clerc [62]):

$$
\begin{gathered}
v_{i}^{\text {new }}=k \times\left\langle v_{i}^{\text {old }}+c_{1} \times \operatorname{rand}() \times\left(s_{i}^{*}-s_{i}^{\text {old }}\right)\right. \\
\left.+c_{2} \times \operatorname{rand}() \times\left(s_{i}^{\#}-s_{i}^{\text {old }}\right)\right\rangle, \\
s_{i}^{\text {new }}=s_{i}^{\text {old }}+v_{i}^{\text {new }},
\end{gathered}
$$

$$
\begin{gathered}
K=\frac{2}{2-\varphi-\sqrt{\varphi^{2}-4 \varphi}}, \\
\phi=c_{1}+c_{2}, \quad \phi>4 .
\end{gathered}
$$

Step 13. After the velocity and position of the particles are updated, they must be verified to determine whether they met (10)-(18) and the set maximal velocity; if these conditions are not met, then the renewal formulae would be used until the renovation meets the restriction formula.

Step 14. Steps 9-13 would be repeated based on iteration times, the Gbest of each iteration time would be compared, and then the iteration times would be used as the condition for stopping the calculation. The final algorithm presents the delivery quantity and target value of the forward and reverse routes.

\section{Illustrative Example and Results Analysis}

This section presents an illustrative example involving a semiconductor supply chain network to demonstrate the effectiveness of the proposed approaches. A typical semiconductor supply chain network is shown in Figure 9. The chain includes a multistage process: obtaining silicon material, material fabrication, wafer fabrication, and a final test. In each stage, there are many enterprises that perform the production processes to fulfill the demand of the customer.

This case programmed one unbalanced supply chain network structure, including forward and reverse logistics, so that downstream suppliers or retailers can return defective products directly to upstream supply chain partners. The manufacturer can restore a broken product's function, depending on the damage, so that the product's purpose is recovered. This case addressed forward and reverse logistics partner selection and quantity delivery problems using a $\{3-$ 4-5-6\} network structure. It also programmed a three-period customer requirement list for a single product. This case supposed that the initial inventory of the first period was zero, transportation losses were considered waste and cannot be reproduced, and different reverse logistics for defective products of different damage levels were programmed. For example, when 10 defective products were generated by the first supplier of the fourth stage, this study assumes that $30 \%$ were returned to the third stage, $30 \%$ were returned to the second stage, and the rest were returned to the first stage. Therefore, the reverse logistics of this study would generate a cross-stage reverse delivery status.

This study considered the productivity restrictions, manufacturing costs, delivery costs, manufacturing quality, and transportation time for all suppliers in selecting supply chain partners. This study also considered the manufacturer's defective product rate and the transportation loss rate of suppliers to form a so-called "unbalanced" supply chain network. The details of all of the suppliers are shown in Figure 10 and Table 1. In addition, the weights of manufacturing costs, 


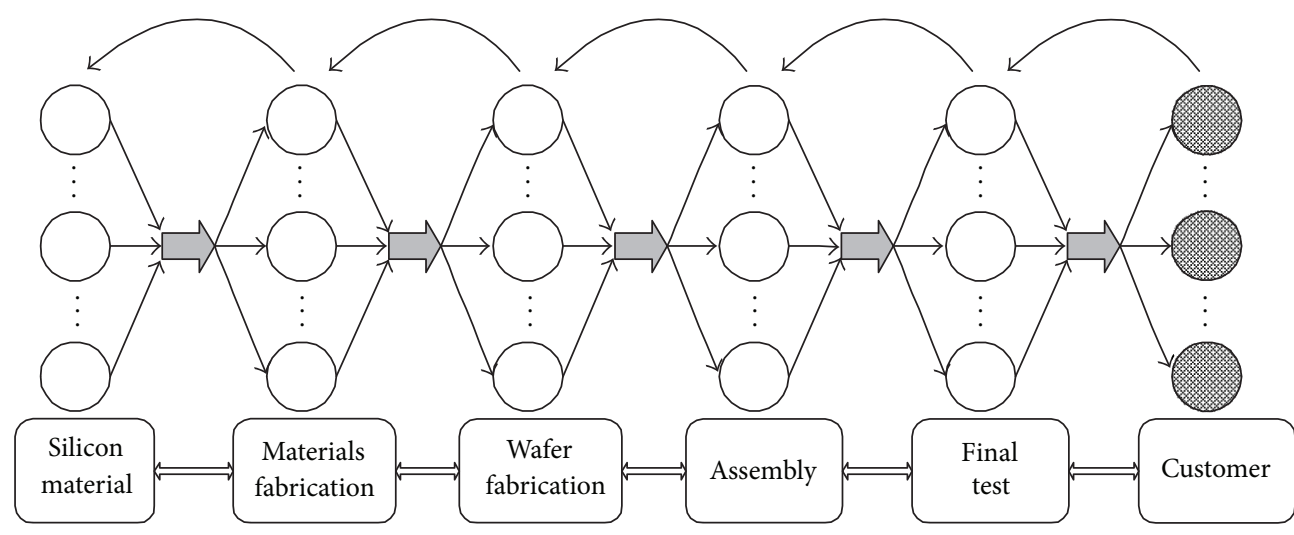

Manufacturing unit

Demand unit

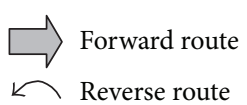

FIGURE 9: Typical supply chain network for semiconductor.

transportation costs, transportation time, and product quality were assumed to be equal.

This study used GA, PSOA_IWM, PSOA_CFM, and PSOA_VMM both to solve the problem of the optimal mathematical model of cross-stage reverse logistics constructed by this study and to determine the optimal parameter values. We used the experimental design to determine the optimal parameter values, and the parameters of the GA used in this study refer to the proposal of Eiben et al. [64]. It is possible to determine the optimal solution when the mutation rate is $0.005-0.01$ and the crossover rate is $0.75-0.95$. This study conducted 16 groups of experimental designs for the parental bodies $(10,20)$, crossover rates $(0.6,0.95)$, mutation rates $(0.02,0.05)$, and generation $(1000,2000)$. Each group was repeated 10 times to obtain the average, and the optimal parameter values were as follows: parental generation (20); crossover rate (0.6); mutation rate (0.05); generation (2000). The experimental results are shown in Table 2.

For the PSO, this study used PSOA_IWM, PSOA_CFM, and PSOA_VMM to solve the problems. PSOA_IWM was suggested by Eberhart and Shi [61], so, when $W$ was between 0.9-1.25, it had a higher chance of achieving the optimal solution; the design of PSOA_IWM parameters was as follows: particle population $(10,20)$, velocity $(30,50)$, weight $(0.4,0.9)$, and generation $(1000,2000)$. Sixteen groups of experiments were designed and each group was repeated 10 times to gain the average convergence value, completion time, and convergence time. The optimal parameters of the experimental results were as follows: particle: 20; weight: 0.4 ; velocity: 50; generation: 2000 . The experimental results are shown in Table 3. PSOA_CFM refers to the $c_{1}=2.05, c_{2}=2.05$ proposed by Clerc [62], $c_{1}=2.8, c_{2}=1.3$ proposed by Zhang et al. [45], the particle $(10,20)$, and the generation $(1000,2000)$; 16 groups of experiments were designed, respectively, with each group being repeated 10 times to acquire the average convergence value, completion time, and convergence time. The optimal parameters of the experimental result were as follows: particle $=20, c_{1}=2.8, c_{2}=1.3$, velocity $=50$, and generation $=2000$. The experimental results are shown in Table 4. PSOA_VMM used the following values: particle $(10,20)$, velocity $(30,50)$, and generation $(1000,2000)$, to conduct eight groups of experimental designs, respectively, with each group repeated 10 times to acquire the average convergence value, completion time, and convergence time. The optimal parameters of the experimental results were as follows: particle $=20$; velocity $=50$; generation $=2000$. The experimental results are shown in Table 5.

For the hardware configuration of this experiment, the CPU was P4-3.0 GHz and the RAM DDR was $512 \mathrm{MB}$. This study used ANOVA and Scheffé to verify system operation times and convergence times and to select the indices for the GA and the three renovation methods. The Scheffé method was first promoted by Scheffé [65] to assess the relationship among the selection factors. ANOVA is a statistical technique that can be used to evaluate whether there are differences between the average values or means across several population groups. The Scheffé method, one of the multiplecomparison approaches, refers to tests designed to establish whether there are differences between particular levels in an ANOVA design, that is, to determine which variable among several independent variables is statistically the most different. The verification results are shown in Tables 6,7 , and 8 .

Tables 6-8 show that all $H_{0}$ are rejected. Finally, the Scheffé method was used to make multiple comparisons of the selection index, system execution time, and convergence time of all the algorithms, and their differences. The Scheffé formula is presented as

$$
\begin{aligned}
& \left(x_{i}-x_{j}-\sqrt{(k-1) F_{\alpha(k-1)(n-k)}} \sqrt{\operatorname{MSE}\left(\frac{1}{n_{i}}+\frac{1}{n_{j}}\right)},\right. \\
& \left.x_{i}-x_{j}+\sqrt{(k-1) F_{\alpha(k-1)(n-k)}} \sqrt{\operatorname{MSE}\left(\frac{1}{n_{i}}+\frac{1}{n_{j}}\right)}\right) .
\end{aligned}
$$




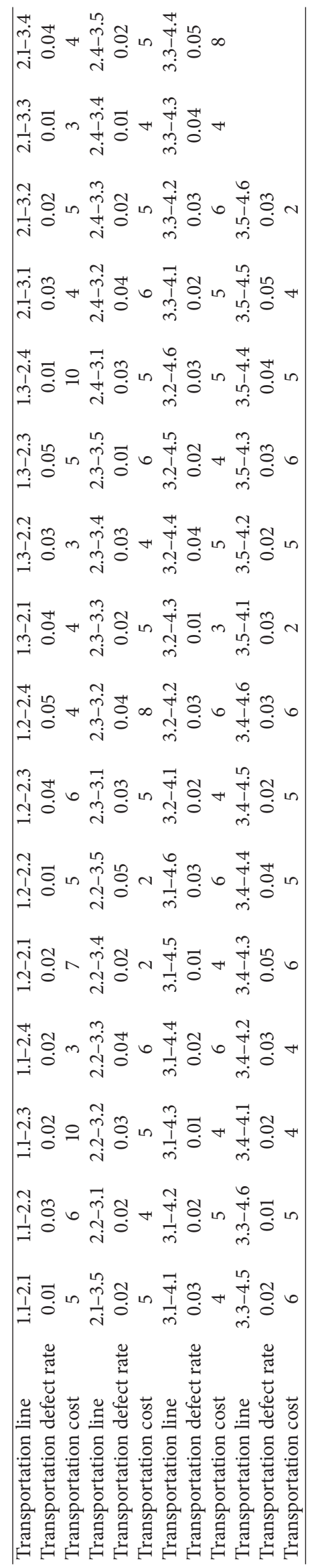




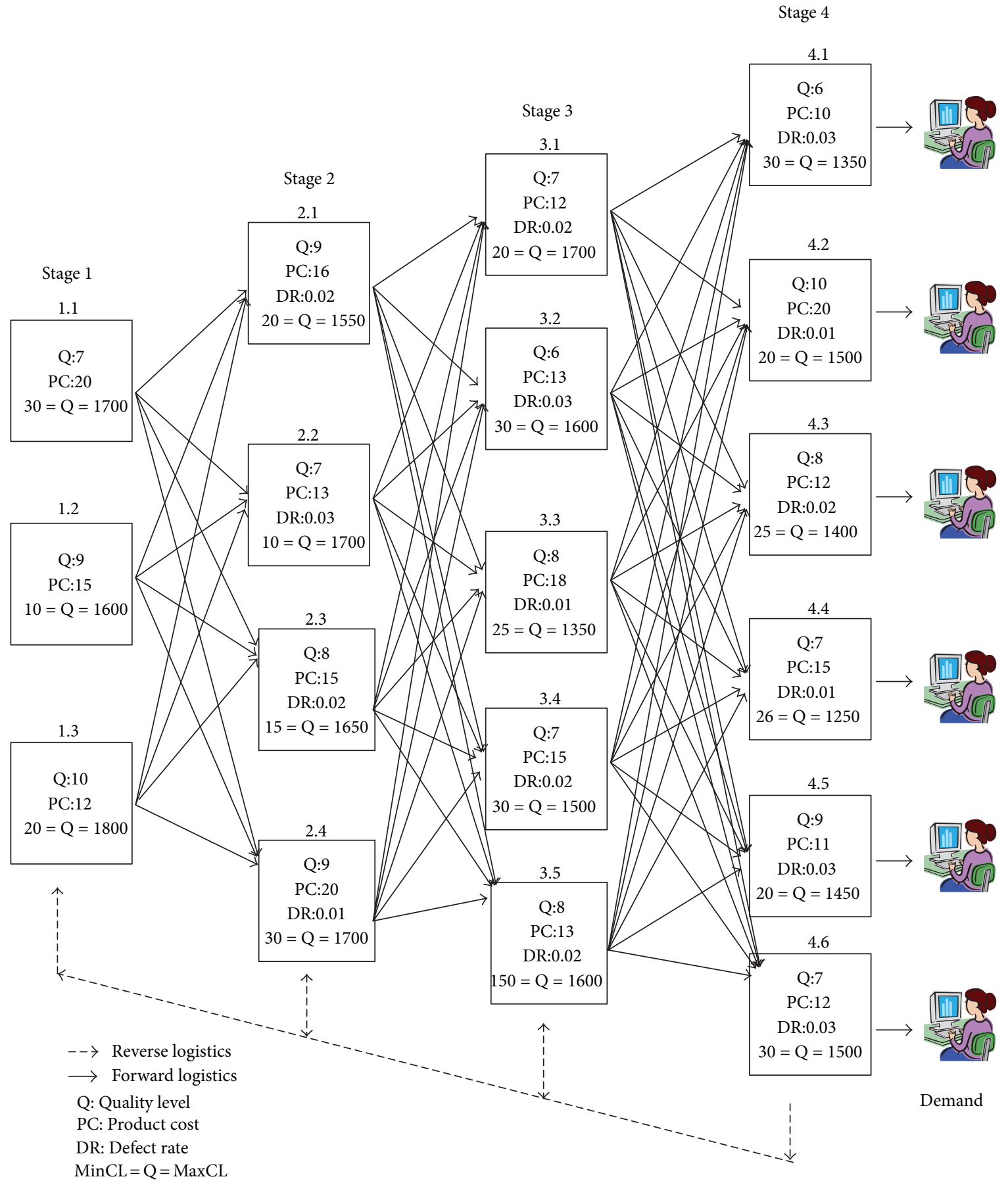

FIGURE 10: $\{3-4-5-6\}$ forward and reverse supply chain network.

Table 9 shows $\mathrm{Obj}_{\text {PSOA_VMM }}>\mathrm{Obj}_{\mathrm{GA}}=\mathrm{Obj}_{\mathrm{PSOA} \text { IWM }}=$ $\mathrm{Obj}_{\text {PSOA_CFM }}$; that is, GA, PSOA_IWM, and PSOA_CFM are all better than PSOA_VMM, and there are no clear differences in the selection indices of the three algorithms. The comparative result of system execution is shown in Table 10, and $F T_{\mathrm{GA}}>F T_{\mathrm{PSOA} \_ \text {IWM }}=F T_{\mathrm{PSOA}_{\text {_VMM }}}=F T_{\mathrm{PSOA} \_\mathrm{CFM}}$ is the three PSO updating methods that are all superior to GA. The convergence times of the algorithms are shown in Table 11, and $C T_{\mathrm{GA}}>C T_{\mathrm{PSOA}_{-} \mathrm{CFM}}>C T_{\mathrm{PSOA}_{-} \text {VMM }}>$
$C T_{\text {PSOA_IWM }}$, that is, PSOA_IWM, has faster convergence speed than PSOA_VMM, PSOA_VMM, and GA. The results show that PSOA_IWM performs better in objective function value solutions, execution times, and convergence times.

For validating the solving capabilities of the proposed approaches in cross-stage reverse logistics problems, more large-scope network structures $\{6-6-6-6\},\{6-6-6-6-6\},\{3-$ $10-10-60\},\{6-8-8-10-30\}$, and $\{8-10-20-20-60\}$ were demonstrated. The analysis results also show that PSOA_IWM has 
TABLE 2: Experimental design results of GA with different groups of parameters.

\begin{tabular}{|c|c|c|c|c|c|c|}
\hline \multicolumn{7}{|c|}{ GA } \\
\hline Generation & Population & Mutation rate & Crossover rate & Convergence time (S) & Execution time (S) & Objective function value \\
\hline \multirow{8}{*}{1000} & \multirow{4}{*}{10} & \multirow{2}{*}{0.02} & 0.6 & 45.65 & 65.22 & 585845.5 \\
\hline & & & 0.95 & 36.91 & 52.72 & 586401.9 \\
\hline & & \multirow{2}{*}{0.05} & 0.6 & 58.88 & 84.12 & 582052.4 \\
\hline & & & 0.95 & 60.12 & 85.88 & 585355.2 \\
\hline & \multirow{4}{*}{20} & \multirow{2}{*}{0.02} & 0.6 & 99.07 & 141.53 & 585731.7 \\
\hline & & & 0.95 & 58.49 & 83.57 & 579156.2 \\
\hline & & \multirow{2}{*}{0.05} & 0.6 & 111.26 & 158.94 & 578879.4 \\
\hline & & & 0.95 & 94.15 & 134.51 & 578760.4 \\
\hline \multirow{8}{*}{2000} & \multirow{4}{*}{10} & \multirow{2}{*}{0.02} & 0.6 & 59.42 & 112.12 & 583037.4 \\
\hline & & & 0.95 & 51.87 & 97.88 & 587388.3 \\
\hline & & \multirow{2}{*}{0.05} & 0.6 & 90.85 & 171.42 & 576988.8 \\
\hline & & & 0.95 & 89.87 & 169.58 & 580298.8 \\
\hline & \multirow{4}{*}{20} & \multirow{2}{*}{0.02} & 0.6 & 88.23 & 166.49 & 576920.3 \\
\hline & & & 0.95 & 72.51 & 136.81 & 579347.1 \\
\hline & & \multirow{2}{*}{0.05} & 0.6 & 155.42 & 293.72 & 575504.7 \\
\hline & & & 0.95 & 133.79 & 252.45 & 576902.9 \\
\hline
\end{tabular}

TABLE 3: Experimental design results of PSOA_IWM with different groups of parameters.

\begin{tabular}{|c|c|c|c|c|c|c|}
\hline & & & & PSOA_IWM & & \\
\hline Generation & Particle & Velocity & Weight & Convergence time (S) & Execution time $(\mathrm{S})$ & Objective function value \\
\hline \multirow{8}{*}{1000} & \multirow{4}{*}{10} & \multirow{2}{*}{20} & 0.4 & 1.17 & 2.49 & 581660.2 \\
\hline & & & 0.9 & 1.26 & 2.69 & 585355.5 \\
\hline & & \multirow{2}{*}{50} & 0.4 & 2.28 & 4.86 & 588147.3 \\
\hline & & & 0.9 & 2.94 & 5.62 & 593565.2 \\
\hline & \multirow{4}{*}{20} & \multirow{2}{*}{20} & 0.4 & 3.45 & 5.21 & 593858.8 \\
\hline & & & 0.9 & 2.71 & 5.77 & 582468.5 \\
\hline & & \multirow{2}{*}{50} & 0.4 & 5.76 & 10.12 & 581133.8 \\
\hline & & & 0.9 & 6.17 & 11.21 & 589921.1 \\
\hline \multirow{8}{*}{2000} & \multirow{4}{*}{10} & \multirow{2}{*}{20} & 0.4 & 2.96 & 4.89 & 612950.3 \\
\hline & & & 0.9 & 2.38 & 5.21 & 581756.6 \\
\hline & & \multirow{2}{*}{50} & 0.4 & 4.69 & 9.24 & 584003.4 \\
\hline & & & 0.9 & 5.10 & 10.26 & 585192.6 \\
\hline & \multirow{4}{*}{20} & \multirow{2}{*}{20} & 0.4 & 4.73 & 9.31 & 591258.4 \\
\hline & & & 0.9 & 5.02 & 10.06 & 580391.2 \\
\hline & & \multirow{2}{*}{50} & 0.4 & 7.56 & 18.88 & 573972.1 \\
\hline & & & 0.9 & 11.94 & 22.34 & 580979.8 \\
\hline
\end{tabular}

better capabilities for the proposed problems, as shown in Table 12. Therefore, this study used PSOA_IWM to solve cross-stage reverse logistics problems.

Tables 13,14, and 15 show the received forward and reverse transportation volume of the three periods; since there were no defective products generated in the first period, there is no returned transportation volume. While this study considers the transportation losses and manufacturer's losses, upstream suppliers produced more products than required to ensure that final demand was met. The quantity of defective products from the second stage was acquired through the defective product rate of all the suppliers. The reverse transportation volume was divided and returned to the upstream supply chain partners, respectively, according to the splitting ratio of defective product quantity. For example, $30 \%$ of the defective products generated by the fourth stage retailer would be returned to the third stage, $30 \%$ to the second stage, and the rest would be returned to the first stage; the third stage would 
TABLE 4: Experimental design results of PSOA_CFM with different groups of parameters.

\begin{tabular}{|c|c|c|c|c|c|c|}
\hline \multicolumn{7}{|c|}{ PSOA_CFM } \\
\hline Generation & Particle & Velocity & $c_{1}, c_{2}$ & Convergence time $(\mathrm{S})$ & Execution time (S) & Objective function value \\
\hline \multirow{8}{*}{1000} & \multirow{4}{*}{10} & \multirow{2}{*}{20} & $2.05,2.05$ & 2.77 & 3.76 & 596860.2 \\
\hline & & & $2.8,1.3$ & 1.84 & 3.92 & 580909.7 \\
\hline & & \multirow{2}{*}{50} & $2.05,2.05$ & 4.85 & 8.18 & 591679.5 \\
\hline & & & $2.8,1.3$ & 4.14 & 7.95 & 575782.2 \\
\hline & \multirow{4}{*}{20} & \multirow{2}{*}{20} & $2.05,2.05$ & 3.37 & 5.05 & 604557 \\
\hline & & & $2.8,1.3$ & 4.43 & 7.29 & 588076.4 \\
\hline & & \multirow{2}{*}{50} & $2.05,2.05$ & 9.01 & 19.16 & 598957.1 \\
\hline & & & $2.8,1.3$ & 8.54 & 15.41 & 583530.4 \\
\hline \multirow{8}{*}{2000} & \multirow{4}{*}{10} & \multirow{2}{*}{20} & $2.05,2.05$ & 6.45 & 9.08 & 579670.6 \\
\hline & & & $2.8,1.3$ & 6.20 & 8.68 & 574969.5 \\
\hline & & \multirow{2}{*}{50} & $2.05,2.05$ & 11.53 & 19.22 & 601022.2 \\
\hline & & & $2.8,1.3$ & 9.86 & 16.44 & 583479.2 \\
\hline & \multirow{4}{*}{20} & \multirow{2}{*}{20} & $2.05,2.05$ & 8.34 & 15.57 & 594554.6 \\
\hline & & & $2.8,1.3$ & 9.91 & 16.53 & 579629.1 \\
\hline & & \multirow{2}{*}{50} & $2.05,2.05$ & 22.64 & 37.74 & 605729.6 \\
\hline & & & $2.8,1.3$ & 18.84 & 31.40 & 574033.9 \\
\hline
\end{tabular}

TABLE 5: Experimental design results of PSOA_VMM with different groups of parameters.

\begin{tabular}{|c|c|c|c|c|c|}
\hline Generation & Particle & Velocity & $\begin{array}{r}\text { PSOA_VMM } \\
\text { Convergence time }(\mathrm{S})\end{array}$ & Execution time (S) & Objective function value \\
\hline \multirow{4}{*}{1000} & \multirow{2}{*}{10} & 20 & 1.97 & 2.95 & 620767.6 \\
\hline & & 50 & 3.89 & 5.81 & 626354.4 \\
\hline & \multirow{2}{*}{20} & 20 & 3.91 & 5.83 & 621080.6 \\
\hline & & 50 & 8.74 & 13.04 & 616409.3 \\
\hline \multirow{4}{*}{2000} & \multirow{2}{*}{10} & 20 & 3.53 & 5.21 & 617751.6 \\
\hline & & 50 & 7.27 & 12.12 & 614025.9 \\
\hline & \multirow{2}{*}{20} & 20 & 7.13 & 10.05 & 614276.1 \\
\hline & & 50 & 14.45 & 24.09 & 609603.7 \\
\hline
\end{tabular}

TABLE 6: ANOVA verification of objective function.

\begin{tabular}{lccc}
\hline Algorithm & Total & Average & Variance \\
\hline GA & 17244286.9 & 574809.5 & 32263393.4 \\
PSOA_IWM & 17206940.5 & 573564.6 & 25588275.7 \\
PSOA_VMM & 18113738.4 & 603791.2 & 106679602.3 \\
PSOA_CFM & 17252708.0 & 575090.2 & 157150309.7 \\
\hline
\end{tabular}

Hypothesis: $H_{0}: \mathrm{Obj}_{\mathrm{GA}}=\mathrm{Obj}_{\mathrm{PSOA} I W M}=\mathrm{Obj}_{\mathrm{PSOA} \_\mathrm{VMM}}=\mathrm{Obj}_{\mathrm{PSOA}_{-} \mathrm{CFM}} H_{1}:$ otherwise

$P$ value $=3.59 E-28 \Rightarrow H_{0}$ is rejected.

TABLE 7: ANOVA verification of completion time.

\begin{tabular}{|c|c|c|c|}
\hline Algorithm & Total & Average & Variance \\
\hline GA & 9207.5 & 306.9 & 3999.0 \\
\hline PSOA_IWM & 567.3 & 18.9 & 8.3 \\
\hline PSOA_VMM & 608.7 & 20.2 & 12.5 \\
\hline PSOA_CFM & 661.2 & 22.0 & 15.5 \\
\hline
\end{tabular}


TABLE 8: ANOVA verification of convergence time.

\begin{tabular}{|c|c|c|c|}
\hline Algorithm & Total & Average & Variance \\
\hline$\overline{\mathrm{GA}}$ & 4662.6 & 155.4 & 96.7 \\
\hline PSO_IWM & 226.9 & 7.5 & 3.2 \\
\hline PSO_VMM & 433.2 & 14.4 & 10.1 \\
\hline PSO_CFM & 567.2 & 18.9 & 12.0 \\
\hline \multicolumn{4}{|c|}{$\begin{array}{c}\text { Hypothesis: } H_{0}: C T_{\mathrm{GA}}=C T_{\mathrm{PSOA}_{\_} I W M}=C T_{\mathrm{PSOA}_{-} \mathrm{VMM}}=C T_{\mathrm{PSOA}_{-} \mathrm{CFM}} H_{1}: \text { otherwise } \\
P \text {-value }=3.25 E-122 \Rightarrow H_{0} \text { is rejected }\end{array}$} \\
\hline
\end{tabular}

TABLE 9: Multiple comparison on objective function.

\begin{tabular}{|c|c|c|c|}
\hline & $\mathrm{Obj}_{\mathrm{GA}}$ & $\mathrm{Obj}_{\mathrm{PSOA} \_I W M}$ & $\mathrm{Obj}_{\mathrm{PSOA} \_V M M}$ \\
\hline $\mathrm{Obj}_{\mathrm{PSOA} \_\mathrm{IWM}}$ & $(-,+)$ & & \\
\hline $\mathrm{Obj}_{\mathrm{PSOA}_{\text {_VMM }}}$ & $(-,-)$ & $(-,-)$ & \\
\hline $\mathrm{Obj}_{\mathrm{PSOA} \mathrm{AFM}_{\mathrm{CF}}}$ & $(+,-)$ & $(-,+)$ & $(+,+)$ \\
\hline
\end{tabular}

TABLE 10: Multiple comparison on execution time.

\begin{tabular}{lccc}
\hline & $F T_{\mathrm{GA}}$ & $F T_{\mathrm{PSOA}_{\_} I W M}$ & \\
\hline$F T_{\text {PSOA_IWM }}$ & $(+,+)$ & & \\
$F T_{\text {PSOA_VMM }}$ & $(+,+)$ & $(-,+)$ & $(-,+)$ \\
$F T_{\text {PSOA_CFM }}$ & $(+,+)$ & $(-,+)$ \\
\hline
\end{tabular}

TABLE 11: Multiple comparison on convergence time.

\begin{tabular}{lccc}
\hline & $C T_{\mathrm{GA}}$ & $C T_{\text {PSOA_IWM }}$ & \\
\hline$C T_{\text {PSOA_IWM }}$ & $(+,+)$ & & \\
$C T_{\text {PSOA_VMM }_{\text {PSOA_VMM }}}$ & $(+,+)$ & $(-,-)$ & $(-,-)$ \\
$C T_{\text {PSOA_CFM }}$ & $(+,+)$ & $(-,-)$ \\
\hline
\end{tabular}

TABLE 12: Analysis results on different network structures.

\begin{tabular}{|c|c|c|c|c|c|}
\hline & Network & GA & PSOA_IWM & PSOA_CFM & PSOA_VMM \\
\hline \multirow{6}{*}{ Objective function } & $3-4-5-6$ & $574809.5^{\mathrm{a}} / 1^{\mathrm{b}}$ & $573564.6 / 1$ & $575096.2 / 1$ & $603791.2 / 2$ \\
\hline & $6-6-6-6$ & $644482.1 / 2$ & $642426.8 / 1$ & $650475.1 / 3$ & $725523.7 / 4$ \\
\hline & $3-10-10-60$ & $972412.2 / 2$ & $954457.3 / 1$ & $980211.5 / 3$ & $1022415.6 / 4$ \\
\hline & $6-6-6-6-6$ & $760460.1 / 2$ & $758655.5 / 1$ & $761552.1 / 3$ & $823544.4 / 4$ \\
\hline & $6-8-8-10-30$ & $1201225.3 / 2$ & $1153252.1 / 1$ & $1242273.4 / 3$ & $1345758.7 / 4$ \\
\hline & $8-10-20-20-60$ & $1685442.3 / 2$ & $1637241.6 / 1$ & $1711412.5 / 3$ & 1811279.4/4 \\
\hline \multirow{6}{*}{ Execution time } & $3-4-5-6$ & $306.9 / 2$ & $18.9 / 1$ & $22.0 / 1$ & $20.2 / 1$ \\
\hline & $6-6-6-6$ & $326.4 / 2$ & $41.8 / 1$ & $42.4 / 1$ & $39.0 / 1$ \\
\hline & $3-10-10-60$ & $621.4 / 4$ & $74.5 / 3$ & $65.8 / 2$ & $61.3 / 1$ \\
\hline & $6-6-6-6-6$ & $533.1 / 3$ & $61.0 / 2$ & $51.3 / 1$ & $48.4 / 1$ \\
\hline & $6-8-8-10-30$ & $782.6 / 4$ & $112.5 / 3$ & $92.1 / 2$ & $85.2 / 1$ \\
\hline & $8-10-20-20-60$ & $997.8 / 4$ & $187.4 / 3$ & $138.5 / 2$ & $102.7 / 1$ \\
\hline \multirow{6}{*}{ Convergence time } & $3-4-5-6$ & $155.4 / 4$ & $7.5 / 1$ & $18.9 / 3$ & $14.4 / 2$ \\
\hline & $6-6-6-6$ & $196.6 / 2$ & $18.6 / 1$ & $22.7 / 1$ & $22.6 / 1$ \\
\hline & $3-10-10-60$ & $415.3 / 3$ & $28.7 / 1$ & $30.2 / 2$ & $31.2 / 2$ \\
\hline & $6-6-6-6-6$ & $302.9 / 3$ & $23.6 / 1$ & $26.5 / 2$ & $27.2 / 2$ \\
\hline & $6-8-8-10-30$ & $557.4 / 3$ & $35.2 / 1$ & $40.7 / 2$ & $42.5 / 2$ \\
\hline & $8-10-20-20-60$ & $632.5 / 4$ & $39.8 / 1$ & $44.2 / 2$ & $48.6 / 3$ \\
\hline
\end{tabular}

\footnotetext{
${ }^{\mathrm{a}}$ Average value; ${ }^{\mathrm{b}}$ ranking (by multiple comparison).
} 
TABLE 13: The first period transportation plan by PSOA_IWM.

\begin{tabular}{|c|c|c|c|c|c|c|c|c|c|c|c|c|c|c|c|c|c|c|c|}
\hline \multirow{2}{*}{ From } & \multirow{2}{*}{ To } & \multicolumn{3}{|c|}{ Stage 1} & \multicolumn{4}{|c|}{ Stage 2} & \multicolumn{5}{|c|}{ Stage 3} & \multicolumn{6}{|c|}{ Stage 4} \\
\hline & & 1.1 & 1.2 & 1.3 & 2.1 & 2.2 & 2.3 & 2.4 & 3.1 & 3.2 & 3.3 & 3.4 & 3.5 & 4.1 & 4.2 & 4.3 & 4.4 & 4.5 & 4.6 \\
\hline \multirow{3}{*}{ Stage 1} & 1.1 & & & & 0 & 0 & 0 & 34 & & & & & & & & & & & \\
\hline & 1.2 & & & & 5 & 646 & 17 & 0 & & & & & & & & & & & \\
\hline & 1.3 & & & & 1615 & 154 & 6 & 15 & & & & & & & & & & & \\
\hline \multirow{4}{*}{ Stage 2} & 2.1 & & & & & & & & 379 & 392 & 190 & 237 & 327 & & & & & & \\
\hline & 2.2 & & & & & & & & 38 & 0 & 8 & 261 & 459 & & & & & & \\
\hline & 2.3 & & & & & & & & 0 & 10 & 10 & 0 & 2 & & & & & & \\
\hline & 2.4 & & & & & & & & 0 & 0 & 48 & 0 & 0 & & & & & & \\
\hline \multirow{5}{*}{ Stage 3} & 3.1 & & & & & & & & & & & & & 6 & 28 & 194 & 163 & 1 & 5 \\
\hline & 3.2 & & & & & & & & & & & & & 0 & 9 & 114 & 13 & 146 & 100 \\
\hline & 3.3 & & & & & & & & & & & & & 0 & 0 & 0 & 27 & 168 & 56 \\
\hline & 3.4 & & & & & & & & & & & & & 126 & 61 & 1 & 154 & 0 & 137 \\
\hline & 3.5 & & & & & & & & & & & & & 291 & 366 & 0 & 8 & 0 & 72 \\
\hline Demand & & & & & & & & & & & & & & 400 & 450 & 300 & 350 & 300 & 350 \\
\hline
\end{tabular}

TABLE 14: The second period transportation plan by PSOA_IWM.

\begin{tabular}{|c|c|c|c|c|c|c|c|c|c|c|c|c|c|c|c|c|c|c|c|}
\hline \multirow{2}{*}{ From } & \multirow{2}{*}{ To } & \multicolumn{3}{|c|}{ Stage 1} & \multicolumn{4}{|c|}{ Stage 2} & \multicolumn{5}{|c|}{ Stage 3} & \multicolumn{6}{|c|}{ Stage 4} \\
\hline & & 1.1 & 1.2 & 1.3 & 2.1 & 2.2 & 2.3 & 2.4 & 3.1 & 3.2 & 3.3 & 3.4 & 3.5 & 4.1 & 4.2 & 4.3 & 4.4 & 4.5 & 4.6 \\
\hline \multirow{3}{*}{ Stage 1} & 1.1 & & & & 29 & 142 & 72 & 158 & & & & & & & & & & & \\
\hline & 1.2 & & & & 120 & 43 & 150 & 24 & & & & & & & & & & & \\
\hline & 1.3 & & & & 576 & 845 & 194 & 128 & & & & & & & & & & & \\
\hline \multirow{4}{*}{ Stage 2} & 2.1 & 12 & 0 & 19 & & & & & 177 & 115 & 148 & 90 & 164 & & & & & & \\
\hline & 2.2 & 9 & 6 & 8 & & & & & 189 & 139 & 51 & 183 & 421 & & & & & & \\
\hline & 2.3 & o & 0 & 0 & & & & & 104 & 78 & 130 & 74 & 12 & & & & & & \\
\hline & 2.4 & 0 & $\mathbf{0}$ & 0 & & & & & 136 & 30 & 15 & 91 & 37 & & & & & & \\
\hline \multirow{5}{*}{ Stage 3} & 3.1 & 1 & 2 & 1 & 3 & 1 & 0 & 0 & & & & & & 67 & 95 & 130 & 69 & 126 & 95 \\
\hline & 3.2 & 2 & 4 & 0 & 2 & $\mathbf{0}$ & 3 & 0 & & & & & & 41 & 54 & 111 & 106 & 27 & 5 \\
\hline & 3.3 & 0 & 0 & 1 & 0 & 1 & 0 & 0 & & & & & & 11 & 2 & 74 & 73 & 81 & 95 \\
\hline & 3.4 & 2 & 0 & 3 & 1 & 1 & 2 & 0 & & & & & & 36 & 45 & 23 & 148 & 127 & 43 \\
\hline & 3.5 & 2 & 1 & 5 & 0 & 1 & 1 & 5 & & & & & & 162 & 165 & 131 & 24 & 92 & 25 \\
\hline \multirow{6}{*}{ Stage 4} & 4.1 & 2 & 0 & 2 & 0 & 4 & 0 & 0 & 0 & 1 & 1 & 0 & 2 & & & & & & \\
\hline & 4.2 & 0 & 2 & 0 & 0 & 1 & 0 & $\mathbf{0}$ & 0 & 1 & 0 & 0 & 0 & & & & & & \\
\hline & 4.3 & 2 & 0 & 0 & 0 & $\mathbf{0}$ & $\mathbf{0}$ & 2 & 0 & $\mathbf{0}$ & 0 & 1 & 1 & & & & & & \\
\hline & 4.4 & 1 & 0 & 0 & 0 & $\mathbf{0}$ & 1 & 0 & 0 & $\mathbf{0}$ & 0 & 0 & 1 & & & & & & \\
\hline & 4.5 & 0 & 3 & 0 & 1 & 2 & $\mathbf{0}$ & $\mathbf{0}$ & 2 & 1 & 0 & $\mathbf{0}$ & 0 & & & & & & \\
\hline & 4.6 & 3 & 1 & 0 & 1 & 2 & $\mathbf{0}$ & $\mathbf{0}$ & 2 & $\mathbf{0}$ & 0 & $\mathbf{0}$ & 1 & & & & & & \\
\hline Demand & & & & & & & & & & & & & & 300 & 350 & 450 & 400 & 430 & 250 \\
\hline
\end{tabular}

Bold data are the reverse transportation volumes.

return $50 \%$ to the second stage, the rest would be returned to the first stage, and the second stage supplier would directly return the defective products to the first stage.

\section{Conclusion and Suggestion}

Enterprises should react to market changes to meet consumer demands in a timely manner to maintain and enhance competitive advantages in this rapidly changing market.
The cross-stage reverse logistics course described in this study could help downstream partners return defective products to the upstream partners directly for maintaining and recovering product function, which in turn could reduce transportation costs and time. With this paper, we have accomplished three tasks. (1) We presented a mathematical model for partner selection and production-distribution planning in multistage supply chain networks with crossstage reverse logistics. Based on our research, a mathematical 
TABLE 15: The third period transportation plan by PSOA_IWM.

\begin{tabular}{|c|c|c|c|c|c|c|c|c|c|c|c|c|c|c|c|c|c|c|c|}
\hline \multirow{2}{*}{ From } & \multirow{2}{*}{ To } & \multicolumn{3}{|c|}{ Stage 1} & \multicolumn{4}{|c|}{ Stage 2} & \multicolumn{5}{|c|}{ Stage 3} & \multicolumn{6}{|c|}{ Stage 4} \\
\hline & & 1.1 & 1.2 & 1.3 & 2.1 & 2.2 & 2.3 & 2.4 & 3.1 & 3.2 & 3.3 & 3.4 & 3.5 & 4.1 & 4.2 & 4.3 & 4.4 & 4.5 & 4.6 \\
\hline \multirow{3}{*}{ Stage 1} & 1.1 & & & & 227 & 24 & 48 & 73 & & & & & & & & & & & \\
\hline & 1.2 & & & & 17 & 47 & 0 & 65 & & & & & & & & & & & \\
\hline & 1.3 & & & & 900 & 738 & 84 & 37 & & & & & & & & & & & \\
\hline \multirow{4}{*}{ Stage 2} & 2.1 & 7 & 3 & 3 & & & & & 133 & 156 & 180 & 239 & 383 & & & & & & \\
\hline & 2.2 & 4 & 2 & 23 & & & & & 172 & 121 & 144 & 234 & 96 & & & & & & \\
\hline & 2.3 & 2 & 4 & 1 & & & & & 45 & 0 & 66 & 27 & 0 & & & & & & \\
\hline & 2.4 & 2 & 1 & 0 & & & & & 3 & 0 & 73 & 33 & 71 & & & & & & \\
\hline \multirow{5}{*}{ Stage 3} & 3.1 & 5 & 0 & 1 & 2 & 2 & 1 & 4 & & & & & & 0 & 4 & 129 & 11 & 134 & 64 \\
\hline & 3.2 & 3 & 2 & 0 & 2 & 0 & 2 & 1 & & & & & & 4 & 3 & 100 & 53 & 57 & 49 \\
\hline & 3.3 & 1 & 0 & 1 & 0 & 1 & 0 & 0 & & & & & & 0 & 81 & 75 & 50 & 139 & 107 \\
\hline & 3.4 & 0 & 1 & 3 & 0 & 0 & 4 & 0 & & & & & & 80 & 50 & 49 & 174 & 36 & 125 \\
\hline & 3.5 & 1 & 5 & $\mathbf{0}$ & 1 & 3 & 1 & 1 & & & & & & 180 & 172 & 64 & 27 & 0 & 77 \\
\hline \multirow{6}{*}{ Stage 4} & 4.1 & 1 & 1 & 1 & 0 & 0 & 2 & 1 & 1 & 1 & 0 & 1 & 0 & & & & & & \\
\hline & 4.2 & 0 & 1 & 0 & 0 & 0 & 1 & 0 & 0 & 1 & 0 & 0 & 0 & & & & & & \\
\hline & 4.3 & 1 & 0 & 2 & 0 & 0 & 0 & 3 & 0 & 0 & 2 & 0 & 1 & & & & & & \\
\hline & 4.4 & 2 & 0 & 0 & 0 & 0 & 1 & 0 & 0 & 0 & 0 & 1 & 0 & & & & & & \\
\hline & 4.5 & 3 & 0 & 2 & 3 & 0 & 0 & 1 & 3 & 0 & 1 & 0 & 0 & & & & & & \\
\hline & 4.6 & 1 & 0 & 2 & 1 & 0 & 1 & 0 & 0 & 1 & 0 & 0 & 1 & & & & & & \\
\hline Demand & & & & & & & & & & & & & & 250 & 300 & 400 & 300 & 350 & 400 \\
\hline
\end{tabular}

Bold data are the reverse transportation volumes.

model for solving multistage supply chain design problems considering the cross-stage reverse logistics has yet to be presented. However, cross-stage reverse logistics should meet the practical logistics operation conditions; therefore, (2) we applied a GA and three PSO algorithms to efficiently solve the mathematical model of cross-stage reverse logistics problems. In this paper, we emphasized the suitability of adopting a GA and three PSOs to find the solution to the mathematical model; hence, (3) we compared four proposed algorithms to find which one works best with the proposed problem. The comprehensive results show that PSOA_IWM has the qualities and capabilities for dealing with a multistage supply chain design problem with cross-stage reverse logistics. Further research should be conducted to employ other heuristic algorithms such as ant colony and simulated annealing for solving this problem. Consideration should also be given to extending this developed approach to encompass more complex problems such as problems involving resource constraints, transportation, and economic batches.

\section{Conflict of Interests}

The authors declare that there is no conflict of interests regarding the publication of this paper.

\section{Acknowledgments}

The authors would like to thank Mr. K. Hsiao for supporting writing of programs and the National Science Council of Taiwan for their partial financial support (Grants no. NSC 1022410-H-027-009 and NSC 101-2410-H-027-006). The authors would also like to acknowledge the editors and anonymous reviewers for their helpful comments and suggestions, which greatly improved the presentation of this paper.

\section{References}

[1] C. J. Vidal and M. Goetschalckx, "Strategic production-distribution models: a critical review with emphasis on global supply chain models," European Journal of Operational Research, vol. 98, no. 1, pp. 1-18, 1997.

[2] B. M. Beamon, "Supply chain design and analysis: models and methods," International Journal of Production Economics, vol. 55, no. 3, pp. 281-294, 1998.

[3] Ş. S. Erengüç, N. C. Simpson, and A. J. Vakharia, "Integrated production/distribution planning in supply chains: an invited review," European Journal of Operational Research, vol. 115, no. 2, pp. 219-236, 1999.

[4] J. Xu, Q. Liu, and R. Wang, "A class of multi-objective supply chain networks optimal model under random fuzzy environment and its application to the industry of Chinese liquor," Information Sciences, vol. 178, no. 8, pp. 2022-2043, 2008.

[5] R. A. Aliev, B. Fazlollahi, B. G. Guirimov, and R. R. Aliev, "Fuzzy-genetic approach to aggregate production-distribution planning in supply chain management," Information Sciences, vol. 177, no. 20, pp. 4241-4255, 2007.

[6] S.-W. Chiou, "A non-smooth optimization model for a twotiered supply chain network," Information Sciences, vol. 177, no. 24, pp. 5754-5762, 2007.

[7] D. Y. Sha and Z. H. Che, "Virtual integration with a multicriteria partner selection model for the multi-echelon manufacturing system," The International Journal of Advanced Manufacturing Technology, vol. 25, no. 7-8, pp. 793-802, 2005. 
[8] D. Y. Sha and Z. H. Che, "Supply chain network design: partner selection and production/distribution planning using a systematic model," Journal of the Operational Research Society, vol. 57, no. 1, pp. 52-62, 2006.

[9] Z. H. Che and Z. Cui, "Unbalanced supply chain design using the analytic network process and a hybrid heuristic-based algorithm with balance modulating mechanism," The International Journal of Bio-Inspired Computation, vol. 3, no. 1, pp. 56-66, 2011.

[10] J. R. Stock, Reverse Logistics, Council of Logistics Management, Oak Brook, Ill, USA, 1992.

[11] B. Trebilcock, "Reverse logistics heroes," Modern Materials Handling, vol. 56, no. 10, pp. 63-65, 2001.

[12] M. Cohen, "Replace. Rebuild or remanufacture," Equipment Management, vol. 16, no. 1, pp. 22-26, 1988.

[13] C. D. White, E. Masanet, C. M. Rosen, and S. L. Beckman, "Product recovery with some byte: an overview of management challenges and environmental consequences in reverse manufacturing for the computer industry," Journal of Cleaner Production, vol. 11, no. 4, pp. 445-458, 2003.

[14] J. Gattorna, Strategic Supply Chain Alignment-Best Practice in Supply Chain Management, Ashgate, 1998.

[15] C. R. Carter and L. M. Ellram, "Reverse logistics: a review of the literature and framework for future investigation," Journal of Business Logistics, vol. 19, no. 1, pp. 85-102, 1998.

[16] S. Dowlatshahi, "Developing a theory of reverse logistics," Interfaces, vol. 30, no. 3, pp. 143-155, 2000.

[17] M. Fleischmann, J. M. Bloemhof-Ruwaard, R. Dekker, E. van der Laan, J. A. E. E. van Nunen, and L. N. van Wassenhove, "Quantitative models for reverse logistics: a review," European Journal of Operational Research, vol. 103, no. 1, pp. 1-17, 1997.

[18] D. S. Rogers and R. Tibben-Lembke, "An examination of reverse logistics practices," Journal of Business Logistics, vol. 22, no. 2, pp. 129-148, 2001.

[19] T. Spengler, H. Püchert, T. Penkuhn, and O. Rentz, "Environmental integrated production and recycling management," European Journal of Operational Research, vol. 97, no. 2, pp. 308326, 1997.

[20] V. Jayaraman, V. D. R. Guide Jr., and R. Srivastava, "A closedloop logistics model for remanufacturing," Journal of the Operational Research Society, vol. 50, no. 5, pp. 497-508, 1999.

[21] A. I. Barros, R. Dekker, and V. Scholten, "A two-level network for recycling sand: a case study," European Journal of Operational Research, vol. 110, no. 2, pp. 199-214, 1998.

[22] L. Kroon and G. Vrijens, "Returnable containers: an example of reverse logistics," International Journal of Physical Distribution \& Logistics Management, vol. 25, no. 2, pp. 56-68, 1995.

[23] M. Fleischmann, Quantitative Models for Reverse Logistics, Springer, Berlin, Germany, 2001.

[24] M. M. Amini, D. Retzlaff-Roberts, and C. C. Bienstock, "Designing a reverse logistics operation for short cycle time repair services," International Journal of Production Economics, vol. 96, no. 3, pp. 367-380, 2005.

[25] M. Fleischmann, P. Beullens, J. M. Bloemhof-Ruwaard, and L. N. van Wassenhove, "The impact of product recovery on logistics network design," Production and Operations Management, vol. 10, no. 2, pp. 156-173, 2001.

[26] R. C. Savaskan, S. Bhattacharya, and L. N. V. Wassenhove, "Closed loop supply chain models with product remanufacturing," Management Science, vol. 50, no. 2, pp. 239-252, 2004.
[27] M. Chouinard, S. D’Amours, and D. Aït-Kadi, "Integration of reverse logistics activities within a supply chain information system," Computers in Industry, vol. 56, no. 1, pp. 105-124, 2005.

[28] Y. Kainuma and N. Tawara, "A multiple attribute utility theory approach to lean and green supply chain management," International Journal of Production Economics, vol. 101, no. 1, pp. 99108, 2006.

[29] A. Nagurney and F. Toyasaki, "Reverse supply chain management and electronic waste recycling: a multitiered network equilibrium framework for e-cycling," Transportation Research E, vol. 41, no. 1, pp. 1-28, 2005.

[30] Y. Nikolaidis, "A modelling framework for the acquisition and remanufacturing of used products," International Journal of Sustainable Engineering, vol. 2, no. 3, pp. 154-170, 2009.

[31] G. Nenes and Y. Nikolaidis, "A multi-period model for managing used product returns, international," Journal of Production Research, vol. 50, pp. 1360-1376, 2012.

[32] M. Salema, A. Barbosa-Póvoa, and A. Novais, "Simultaneous design and planning of supply chains with reverse flows: a generic modelling framework," European Journal of Operational Research, vol. 203, no. 2, pp. 336-349, 2010.

[33] T. Pinto-Varela, A. P. Barbosa-Póvoa, and A. Q. Novais, "Biobjective optimization approach to the design and planning of supply chains: economic versus environmental performances," Computers and Chemical Engineering, vol. 35, no. 8, pp. 14541468, 2011.

[34] S. Amin and G. Zhang, "A proposed mathematical model for closed-loop network configuration based on product life cycle," International Journal of Advanced Manufacturing Technology, vol. 58, no. 5-8, pp. 791-801, 2012.

[35] M. Huang, M. Song, L. H. Lee, and W. K. Ching, "Analysis for strategy of closed-loop supply chain with dual recycling channel," International Journal of Production Economics, vol. 144, no. 2, pp. 510-520, 2013.

[36] P. L. Meena and S. P. Sarmah, "Multiple sourcing under supplier failure risk and quantity discount: a genetic algorithm approach," Transportation Research E, vol. 50, pp. 84-97, 2013.

[37] B. Stojanovic, M. Milivojevic, M. Ivanovic, N. Milivojevic, and D. Divac, "Adaptive system for dam behavior modeling based on linear regression and genetic algorithms," Advances in Engineering Software, vol. 65, pp. 182-190, 2013.

[38] R. Belevičius, D. Jatulis, and D. Šešok, "Optimization of tall guyed masts using genetic algorithms," Engineering Structures, vol. 56, pp. 239-245, 2013.

[39] Z. H. Che and C. J. Chiang, "A modified Pareto genetic algorithm for multi-objective build-to-order supply chain planning with product assembly," Advances in Engineering Software, vol. 41, no. 7-8, pp. 1011-1022, 2010.

[40] S. P. Nachiappan and N. Jawahar, "A genetic algorithm for optimal operating parameters of VMI system in a two-echelon supply chain," European Journal of Operational Research, vol. 182, no. 3, pp. 1433-1452, 2007.

[41] H. S. Wang and Z. H. Che, "An integrated model for supplier selection decisions in configuration changes," Expert Systems with Applications, vol. 32, no. 4, pp. 1132-1140, 2007.

[42] Z. H. Che and T. A. Chiang, "Designing a collaborative supply chain plan using the analytic hierarchy process and genetic algorithm with cycle time estimation," International Journal of Production Research, vol. 50, no. 16, pp. 4426-4443, 2012.

[43] J. Kennedy and R. Eberhart, "Particle swarm optimization," in Proceedings of the IEEE International Conference on Neural Networks, vol. 4, pp. 1942-1948, December 1995. 
[44] Z. Liao and J. Rittscher, "A multi-objective supplier selection model under stochastic demand conditions," International Journal of Production Economics, vol. 105, no. 1, pp. 150-159, 2007.

[45] L.-P. Zhang, H.-J. Yu, and S.-X. Hu, "Optimal choice of parameters for particle swarm optimization," Journal of Zhejiang University Science A, vol. 6, no. 6, pp. 528-534, 2005.

[46] X. H. Shi, Y. C. Liang, C. Lu, H. P. Lee, and Q. X. Wang, "Particle swarm optimization-based algorithms for TSP and generalized TSP," Information Processing Letters, vol. 103, no. 5, pp. 169-176, 2007.

[47] Z. H. Che, "PSO-based back-propagation artificial neural network for product and mold cost estimation of plastic injection molding," Computers and Industrial Engineering, vol. 58, no. 4, pp. 625-637, 2010.

[48] Z. H. Che, "A particle swarm optimization algorithm for solving unbalanced supply chain planning problems," Applied Soft Computing, vol. 12, no. 4, pp. 1279-1287, 2012.

[49] C. Priya and P. Lakshmi, "Particle swarm optimisation applied to real time control of spherical tank system," International Journal of Bio-Inspired Computation, vol. 4, no. 4, pp. 206-216, 2012.

[50] L. Ali, S. L. Sabat, and S. K. Udgata, "Particle swarm optimisation with stochastic ranking for constrained numerical and engineering benchmark problems," International Journal of BioInspired Computation, vol. 4, no. 3, pp. 155-166, 2012.

[51] E. García-Gonzalo and J. L. Fernández-Martínez, "A brief historical review of particle swarm optimization (PSO)," Journal of Bioinformatics and Intelligent Control, vol. 1, no. 1, pp. 3-16, 2012.

[52] L. Ali and S. L. Sabat, "Particle swarm optimization based universal solver for global optimization," Journal of Bioinformatics and Intelligent Control, vol. 1, no. 1, pp. 95-105, 2012.

[53] M. Salehi Maleh, S. Soleymani, R. Rasouli Nezhad, and N. Ghadimi, "Using particle swarm optimization algorithm based on multi-objective function in reconfigured system for optimal placement of distributed generation," Journal of Bioinformatics and Intelligent Control, vol. 2, no. 2, pp. 119-1124, 2013.

[54] H. M. Abdelsalam and A. M. Mohamed, "Optimal sequencing of design projects' activities using discrete particle swarm optimisation," International Journal of Bio-Inspired Computation, vol. 4, no. 2, pp. 100-110, 2012.

[55] Y. Dong, J. Tang, B. Xu, and D. Wang, "An application of swarm optimization to nonlinear programming," Computers and Mathematics with Applications, vol. 49, no. 11-12, pp.1655-1668, 2005.

[56] P.-Y. Yin and J.-Y. Wang, "A particle swarm optimization approach to the nonlinear resource allocation problem," Applied Mathematics and Computation, vol. 183, no. 1, pp. 232-242, 2006.

[57] A. Salman, I. Ahmad, and S. Al-Madani, "Particle swarm optimization for task assignment problem," Microprocessors and Microsystems, vol. 26, no. 8, pp. 363-371, 2002.

[58] W. A. McCall, Measurement, Macmillan, New York, NY, USA, 1939.

[59] Z. H. Che, "A genetic algorithm-based model for solving multiperiod supplier selection problem with assembly sequence," International Journal of Production Research, vol. 48, no. 15, pp. 4355-4377, 2010.

[60] D. E. Goldberg, Genetic Algorithms in Search Optimization and Machine Learning, Addison-Wesley, New York, NY, USA, 1988.

[61] R. C. Eberhart and Y. Shi, "Comparison between genetic algorithms and particle swarm optimization," in Proceedings of the 7th Annual Conference on Evolutionary Programming, pp. 611616, Springer, Berlin, Germany, 1998.

[62] M. Clerc, "The swarm and the queen: towards a deterministic and adaptive particle swarm optimization," in Proceeding of the IEEE Congress on Evolutionary Computation, vol. 3, pp. 19511957, 1999.

[63] R. Eberhart and J. Kennedy, "New optimizer using particle swarm theory," in Proceedings of the 6th International Symposium on Micro Machine and Human Science, pp. 39-43, October 1995.

[64] Á. E. Eiben, R. Hinterding, and Z. Michalewicz, "Parameter control in evolutionary algorithms," IEEE Transactions on Evolutionary Computation, vol. 3, no. 2, pp. 124-141, 1999.

[65] H. A. Scheffé, "A method for judging all contrasts in the analysis of variance," Biometrika, vol. 40, no. 1-2, pp. 87-104, 1953. 

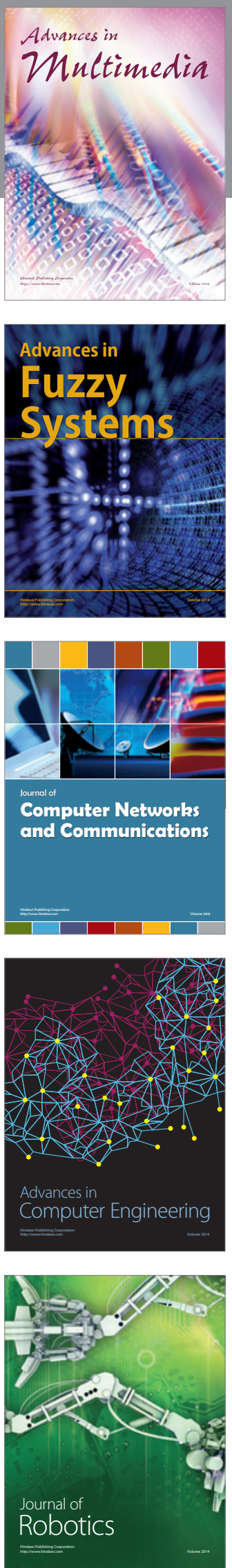

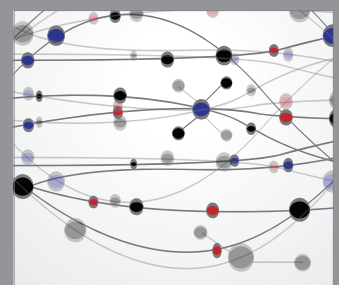

The Scientific World Journal
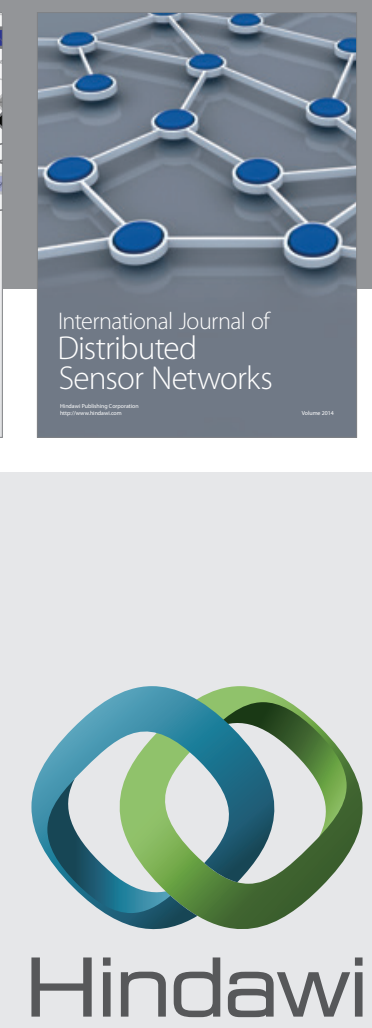

Submit your manuscripts at

http://www.hindawi.com
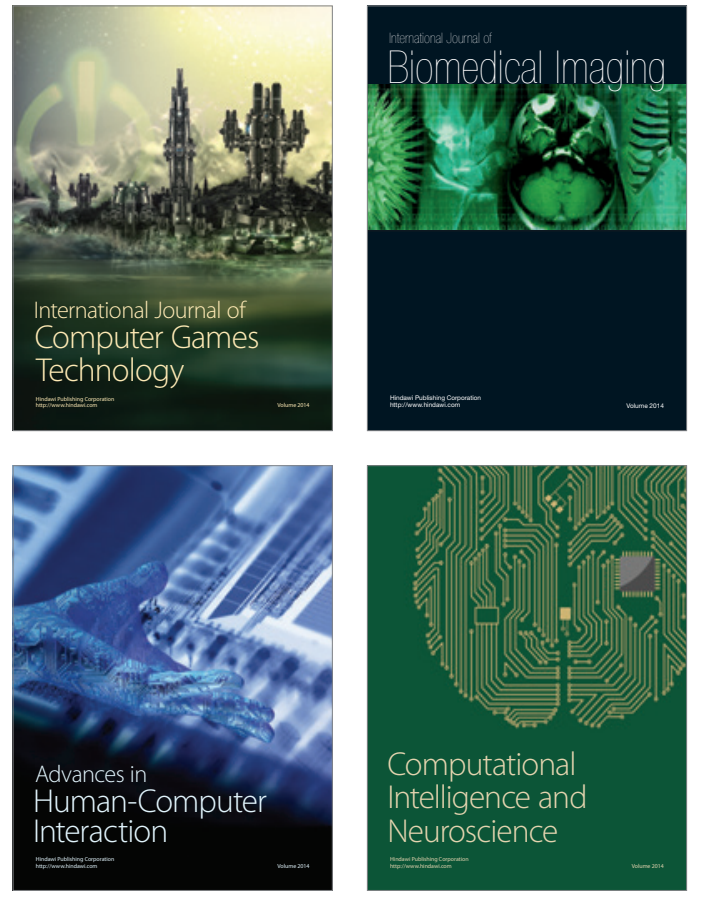
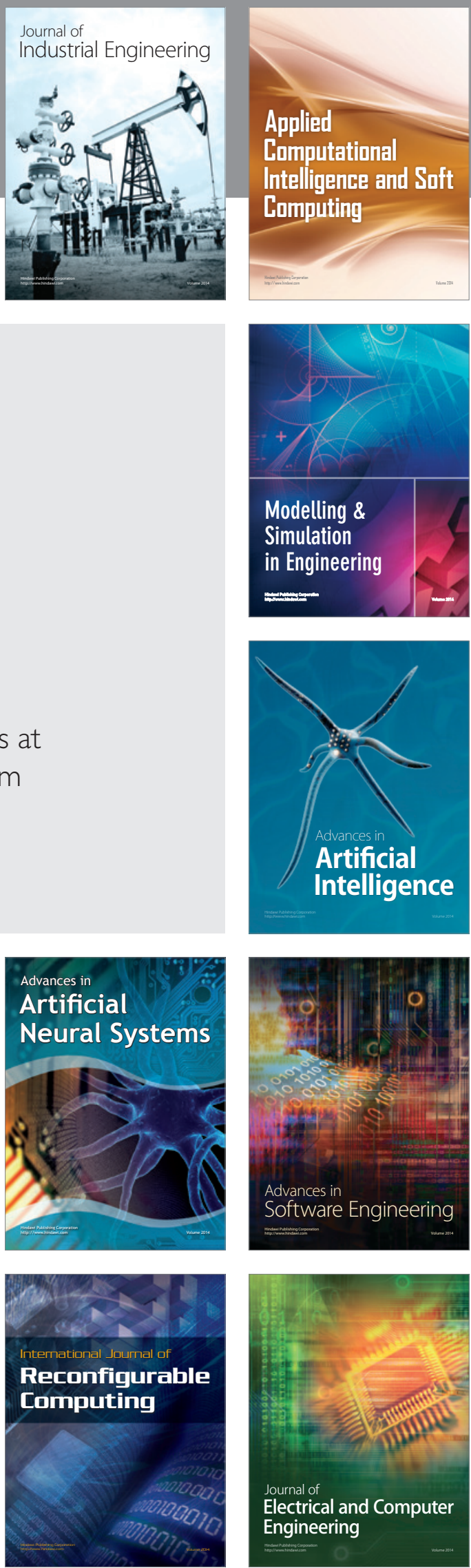